\section{No todas las calles fueron siempre calles. Las avenidas de la periferia de Santiago: camino Los Morros}

Rosanna Forray

Escuela de Arquitectura, Facultad de Arquitectura, Diseño y Estudios Urbanos, Pontificia Universidad Católica de Chile, Chile.

\section{Christian Saavedra}

Escuela de Arquitectura, Facultad de Arquitectura, Diseño y Estudios Urbanos, Pontificia Universidad Católica de Chile, Chile.

Recibido: 5 de mayo de 2017. Aceptado: 18 de octubre de 2017.

\title{
Resumen
}

No todas las calles fueron siempre calles. Las calles de las áreas centrales de muchas ciudades sudamericanas se configuraron a partir de la división del suelo en manzanas y predios a lo largo de ejes ortogonales de circulación y de acceso a las propiedades que les daban forma y las dotaban de actividad (habitualmente en Damero). Otra cosa son las rutas, caminos o calzadas que desde la colonia se prolongaban desde los ejes principales o los umbrales de las ciudades hacia los poblados aledaños y distantes formando sistemas de asentamientos cuyos vínculos se basaban en las relaciones económicas, militares o religiosas del territorio bajo el control de estas ciudades. Frecuentemente las avenidas periféricas de nuestras ciudades contemporáneas fueron caminos o rutas. Este artículo profundiza en una investigación sobre la Gran Avenida, eje mayor que atraviesa la ciudad de Santiago de Chile, desde el centro histórico y administrativo hasta el sur pobre, enfocándose en el tramo denominado avenida Los Morros, en su evolución de camino a avenida. El interés en este tramo del otrora camino colonial radica en que nos permite observar cómo su condición de camino ha sido determinante en el desarrollo de su entorno urbano actual y en la paulatina conformación de la avenida como lugar de lo público.

Palabras clave

Caminos coloniales Avenidas periféricas Espacio público Transporte Santiago de Chile

\section{Palavras-chave}

Caminhos coloniais Avenidas periféricas Espaço público

Transporte Santiago de Chile

\section{Not all street have always been streets. The avenues of the periphery of Santiago: Los Morros road}

\author{
Abstract \\ Not all streets have always been streets. Streets from central districts in many South \\ American cities were configured as a result of land subdivision in blocks and plots
}

Keywords

Colonial roads Peripheral avenues Public space

Transport Santiago de Chile 
along orthogonal arteries for circulation and access to properties that shaped them and gave them life. Something quite different are the routes, roads, and driveways which since colonial times have extended from main axes or city thresholds towards nearby or distant towns forming settlement systems whose relationships were based on economic, military or religious links concerning the territory controlled by these cities. Peripheral avenues in our contemporary cities were often roads or routes. This article focuses on a research about the Gran Avenida, one of the main arteries crossing Santiago de Chile, from downtown to the poor southern part of the city, to focus in Avenida Los Morros and its evolution from road to urban avenue. The interest upon this section of the once colonial road lies in the fact that it allows us to observe how its condition of road has been critical to the development of its current urban environment, and to the gradual constitution of this avenue as a public domain.

\section{Introducción}

No todas las calles fueron siempre calles. De hecho las calles de las áreas centrales de nuestras ciudades se configuraron como tales desde su origen, siguiendo la estructura del damero que respondía a los principios coloniales de la división del suelo y la distribución de la propiedad. Así, manzanas divididas en predios otorgados por encomienda, se alineaban en torno a ejes ortogonales de circulación y acceso a las propiedades que poco a poco cobraban forma y se dotaban de actividad. De este modo, la calle iba adquiriendo estatus como lugar cívico, de relaciones e intercambios económicos, sociales, simbólicos, además de ser espacio del movimiento. Otra cosa son las rutas, caminos o calzadas que desde la colonia -e incluso desde tiempos precolombinos- se prolongaban desde las calles principales o los umbrales de las ciudades hacia poblados aledaños y distantes con los cuales formaban sistemas de asentamientos vinculados por relaciones económicas, militares o religiosas con el territorio bajo su control.

Esta situación que parece un lugar común, es una clave para comprender la progresiva formación de las avenidas principales de las periferias urbanas en nuestras ciudades, allí donde la ciudad se ha desarrollado paulatinamente en torno a los caminos originales que la conectaban con los territorios próximos y lejanos que las alimentaban; allí donde se juntaba el bajo pueblo, en palabras de Gabriel Salazar, para comerciar y festejar; donde, no sin conflicto se fueron instalando, al ritmo de los cambios en los medios de transporte, barrios y poblaciones otorgando estatus urbano a quienes no lo tenían.

Muchas de las avenidas principales de las periferias de nuestras ciudades de hoy fueron los caminos o rutas de antaño. El crecimiento radial que caracterizó a Santiago, así como a muchas ciudades latinoamericanas, hasta bien entrado el siglo XX se hizo en torno a estos caminos que se fueron conformando como rutas de acceso a los campos que se subdividen en su entorno, rutas de circulación de mercancías desde y hacia el centro de la ciudad, que progresivamente fueron transformándose en avenidas principales en que convergen barrios con historias distintas, donde se concentran el comercio y los servicios, donde se insertan los recorridos estructurantes del transporte público y al mismo tiempo, donde se va construyendo paulatinamente espacio público e identidad.

El artículo parte de una investigación anterior sobre la Gran Avenida, eje mayor que atraviesa la ciudad de Santiago desde el centro hacia el sur pobre, para focalizarse en un tramo de ella conocido como Avenida Los Morros, y profundizar en su transformación desde camino hacia avenida. El interés de hacer foco en este tramo de la otrora ruta colonial, radica en que nos permite observar cómo su condición de camino ha sido determinante en el particular desarrollo de su entorno urbano actual y en la tardía conformación del estatus cívico de avenida que ha logrado constituir para una vasta 
área residencial que concentra familias de menores ingresos. Esta es a nuestro juicio una muestra de procesos similares de formación de las avenidas de las periferias de Santiago, como las de muchas ciudades latinoamericanas.

Este texto se organiza en cinco etapas de la formación de Los Morros y de su transición de camino a avenida: el camino colonial, la gestación de un proceso temprano de urbanización de suelo de escasa renta, la transición de camino a calle o el proceso de conformación de sus bordes urbanos, la transición de calle a avenida, y la producción de espacio público más allá del transporte, un proyecto de avenida.

\section{6-1810 ¿camino inca o camino colonial?}

Si la actual Avenida Los Morros es parte de un camino incaico, de un camino real construido por Pedro de Valdivia para salir de Santiago hacia los territorios del sur u otro, es aún objeto de debate. La investigación sobre los caminos que atravesaban la cuenca de Santiago a la llegada de los españoles se encuentra aún en curso. No hay acuerdo concluyente entre arqueólogos e historiadores, estudiosos de la ocupación incaica de los valles del Mapocho y del Maipo sobre el estatus que tenía este territorio dentro del Imperio ni sobre el origen de las redes de caminos que se desprendían de la cuadrícula de la ciudad fundada por Pedro de Valdivia en 1541. Se suele pensar -y aún está en discusión- que la traza de la actual Avenida Los Morros corresponde un camino Inca ${ }^{1}$, sin embargo es plausible la tesis elaborada por Rubén Stehberg y Gonzalo Sotomayor en su artículo "Mapocho Incaico" (2012:122-125) a partir de tres documentos: un relato y dos planos. En relato de la época, reportado por los autores, el cronista Vivar se refiere a una cabalgata por las riberas del río Maipo a mediados de 1543, en que Pedro de Valdivia "Halló un sitio donde los Incas hicieron un puente cuando vinieron a conquistar esta tierra y estaba el sitio arruinado. Fue más adelante y halló sitio y lugar oportuno..." (Vivar 1966[1558]:84, cit. en Stehberg et al. 2012:124). Por su parte los dos planos, que datan de mediados del 1700, corresponden al "Plano del Llano del Maipo" elaborado por Lozada (Figura 1) y al Plano "Demostración del Río de Maipo" realizado por Nicolás de Albos Padilla (Figura 2). Ambos muestran los caminos que atravesaban el Llano del Maipo hacia el sur y según los autores coinciden con lo relatado por Vivar. A partir de lo cual sostienen que:

\section{[...] el "Camino del P(uen)te Antiguo" constituiría un segmento del camino del Inca-también designado como "camino que va a los Promaucaes" mientras que el "Cam(in)o R(ea)l de el Puente" compondría el camino que mandó construir Pedro de Valdivia (Stehberg y Sotomayor, 2012:124).}

El Plano de El Llano del Maipo (Figura 1), elaborado en 1775-1761 con el objetivo de consignar las medidas de la extensión de la chacra de Lepe (polígono amarillo) y su localización dentro del valle del Maipo, muestra los caminos que salían de Santiago hacia el río Maipo, atravesando el Llano, una vasta extensión localizada entre el sur de la ciudad y dicho río. Al oriente se observa el denominado Camino del Chequén (en amarillo) que se bifurca en el Camino del Chequencillo. Al centro (en rojo) se observa el Camino del Puente Antiguo que conducía al Puente Antiguo el cual, según Stehberg y Sotomayor, formaba parte del otrora Camino del Inca. Inmediatamente hacia el poniente (en azul) se encuentra el Camino Real del Puente que los autores asignan a Pedro de Valdivia; y al extremo poniente (en verde) el Camino de Tango que conducía a un área denominada Vado en el borde río. En base a las demostraciones de dichos autores, podemos concluir que el trazado de la actual Avenida Los Morros no corresponde al camino incaico, como se suele pensar.
1. Incluso nosotros mismos hemos respaldado esta tesis en artículos anteriores (Forray, Figueroa, Hidalgo 2013). 


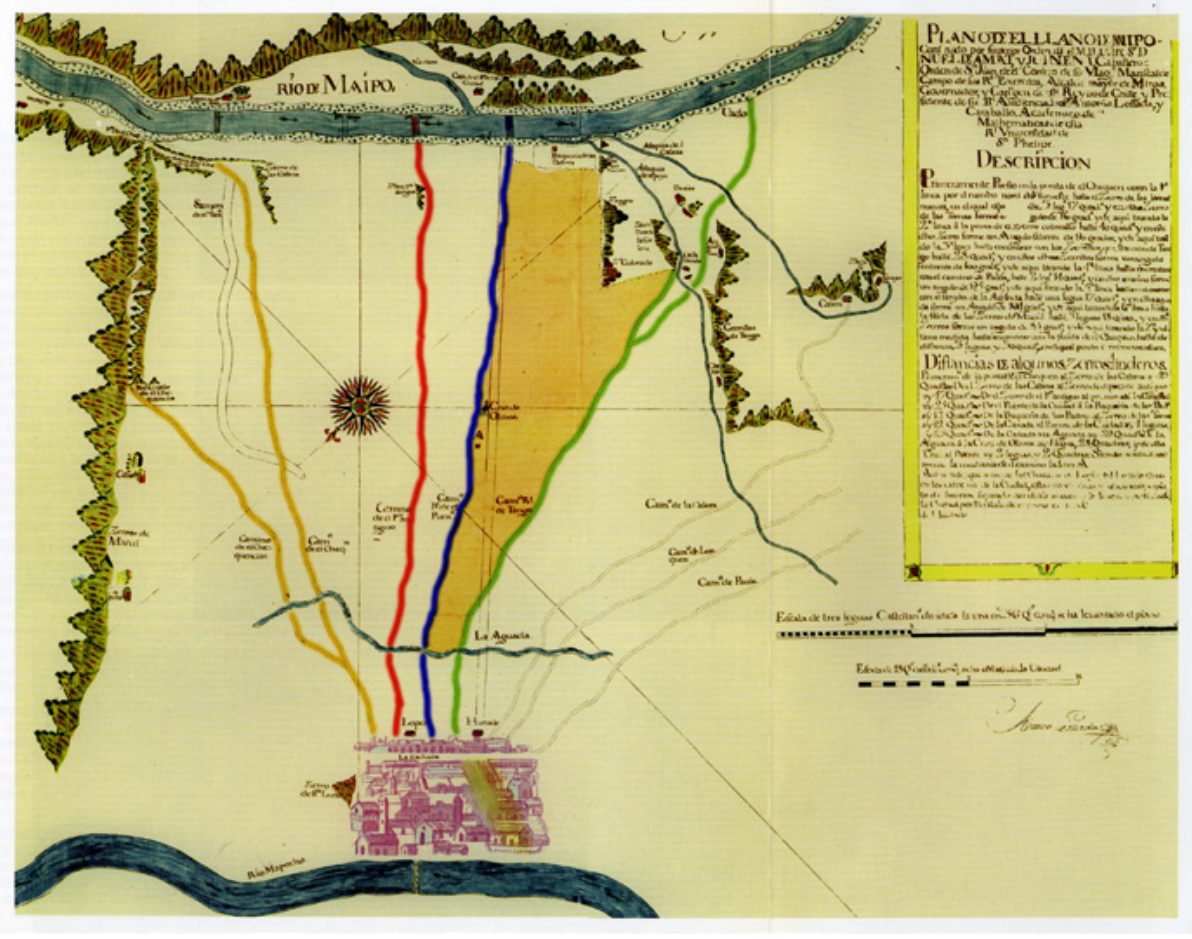

El siguiente punto en discusión, se refiere a las calles actuales que corresponden a dichos caminos. Si intentamos reconocer en el plano de Lozada (Figura 1) los caminos por su proximidad y localización respecto a los cerros, observaremos que al parecer este contiene errores en sus nominaciones. Así, el que aparece como Cerro de las Cabras es el actual Cerro La Ballena, el que aparece como Cerro del Puente Antiguo es el actual Cerro Las Cabras. Esta situación se confirma si se trazan las distancias que consigna la leyenda de dicho plano en su segundo párrafo “[...] de la punta del Chequén al Cerro de las Cabras hay 29 cuadras. Del Cerro de las Cabras al Cerro del Puente Antiguo hay 17 cuadras". De este modo, podríamos pensar que el Camino del Puente Antiguo que rodea al Cerro del Puente Antiguo por su lado poniente en este plano, no corresponde a ninguna calle actual reconocible salvo la Avenida La Serena (hoy carretera Acceso Sur). Del mismo modo, el que aparece como Camino Real del Puente podría ser la actual Avenida Santa Rosa, ya que la leyenda del plano señala que "Del Cerro del Puente Antiguo al Puente de la Ciudad [presumiblemente Puente Nuevo] hay 25 cuadras" (Leyenda Plano Antonio de Lozada 1755-61). Esta distancia corresponde, con una aproximación sorprendente, a la que existe actualmente entre el Cerro las Cabras y el punto en que Avenida Santa Rosa llega al río.

En el Plano de 1746, elaborado por Nicolás de Abos (Figura 2), aparecen en el Llano cuatro caminos cuyos trazados conducen al sur. Los dos situados al oriente (en amarillo) son nombrados como Camino del Cerro de las Cabras por su relación con el cerro nominado en el plano con el mismo nombre, uno de los cuales podría corresponder al Camino el Chequén del plano de Lozada y el otro, al Camino del Puente Antiguo, camino del Inca según Stehberg y Sotomayor. Hacia el poniente (en rojo), el nombrado como Camino del Puente que bordea el denominado en el plano como Cerro Negro podría corresponder al Camino Real del Puente del plano de Lozada. Finalmente, un tercer camino (en verde) nombrado en este plano como Camino Real del Bao, que se aproxima al río acercándose al Cerro de los Morros, podría corresponder al Camino Real de Tango del Plano de Lozada. A este punto no coincidimos con la lectura que hacen Stehberg y Sotomayor del plano de Abos. Los autores proponen que en este plano el Camino del Puente corresponde al Camino del
Figura 1. Plano de El Llano de Maipo (1755-1761 aprox.), realizado por Antonio Lozada. Nota: Muestra cuatro caminos que conducen hacia el río Maipo, dos lo cruzan: el "Camino del Puente Antiguo" en rojo, supuestamente correspondiente al camino del Inca, y el "Camino Real del Puente en azul", supuestamente construido por Pedro de Valdivia hacia 1543 . Hacia el oriente se encuentra el "Camino de Chequén" en amarillo y hacia el poniente, el "Camino de Tango" en verde. Fuente: Vicuña Mackenna 1997 [1869], modificado por los autores. 


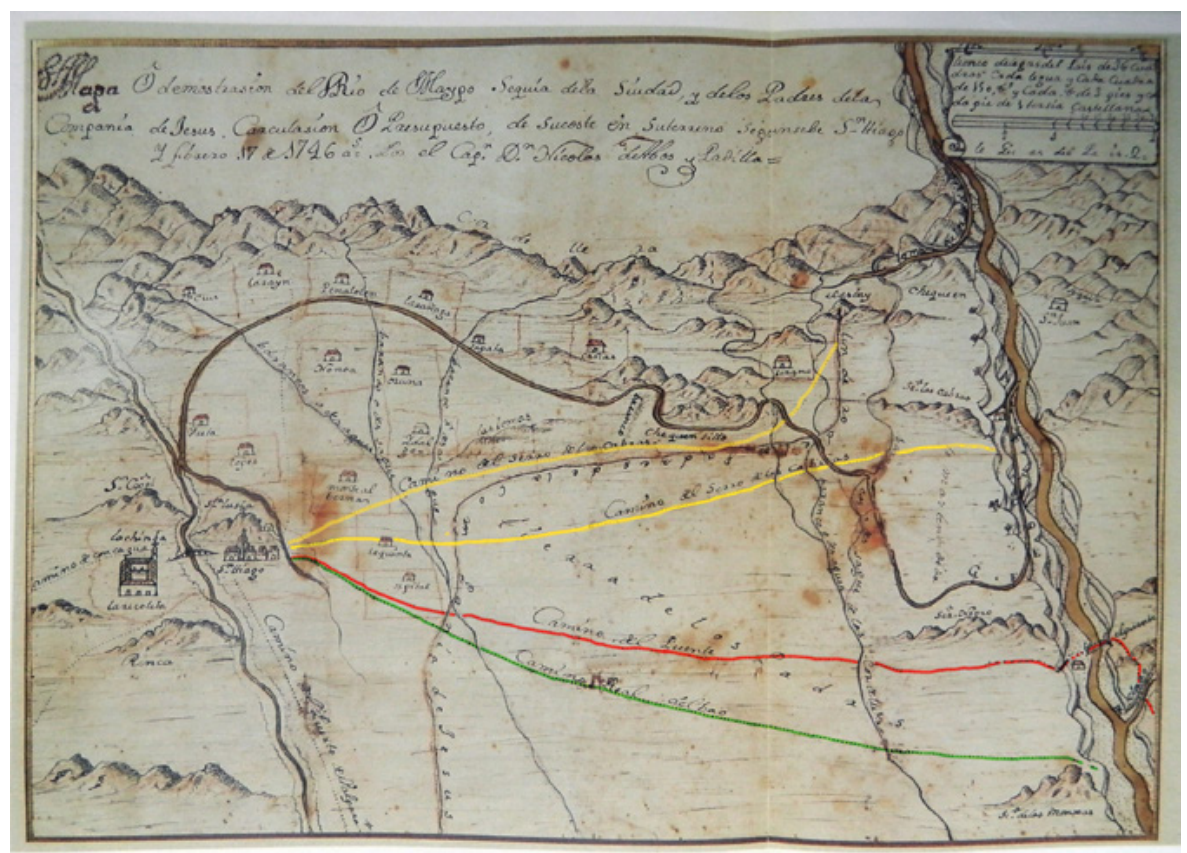

Puente Antiguo de Lozada, y que el Camino Real del Bao al que en el plano de Lozada se llama Camino Real del Puente (2016:124). Teniendo en cuenta las relaciones entre caminos y cerros, a nuestro juicio el Camino del Puente Antiguo del Plano de Lozada corresponde al Camino del Cerro de las Cabras del Plano de Abos, el Camino Real del Puente de Lozada corresponde al Camino del puente de Abos y el Camino de Tango al Camino Real del Vao (Figuras 1 y 2).

Por otra parte, según aparece en los archivos de la Real Audiencia y en los escritos de Ginés De Lillo (1602-1605), el Llano en esta época era una extensión de tierra infértil, sin embargo desde muy temprano -segunda mitad del siglo XVI- ya había sido dividida para ser entregada en encomiendas, las que fueron paulatinamente subdivididas en hijuelas entre los herederos de los encomenderos. Autores como Echaíz (1975) y Romero (2016) señalan que hacia 1627 Mateo Lepe inscribe la propiedad que se extendía de oriente a poniente entre el Camino del Puente y el Camino de Talagante, y de norte a sur, entre el Zanjón de la Aguada y las propiedades de los Padres Jesuitas antes de llegar al río Maipo. También coinciden en que en 1732 sus sucesores la dividen en dos hijuelas tomando como eje el Camino de Tango, y en que entre esta fecha y el fin del 1700, la hijuela que se extiende al oriente de dicho camino hasta el Camino del Puente, no sufre grandes cambios y es conocida como Llano de Lepe. De hecho, según los contenidos de la leyenda del plano de Lozada (Figura 1), éste fue aparentemente elaborado para consignar los límites de dicha hijuela. Sin embargo no aparece en este plano ninguna huella que muestre una vía en el eje del predio del Llano de Lepe que pudiese indicar la presencia de un camino correspondiente al actual trazado de la Av. Gran Avenida-Los Morros.

Hasta aquí las dudas no han sido completamente despejadas, nada nos permite afirmar aún que el trazado actual de Gran Avenida-Los Morros corresponda a un camino inca o a uno colonial. Tanto la interpretación de Stehberg y Sotomayor como la identificación topográfica de los caminos a partir de la información contenida en la leyenda del Plano de Lozada, cuestionan esta tesis. No obstante, hay tres puntos hasta aquí no considerados que abren nuevas pistas, pero no son concluyentes. El primero se refiere a la existencia del Camino Real de Chada que según el "Informe de la Comisión de Trabajo Autónomo Mapuche" (2003:s/p), desde tiempos incaicos conducía desde la ribera
Figura 2. "Mapa y Demostración del Río de Maipo. Sequía de la ciudad, y de los Padres de la Compañía de Jesús. Calculación y Presupuesto, de su coste en su terreno según se ve Santiago y febrero 17 de 1746 ", realizado por el Capitán don Nicolás de Abos Padilla. Muestra cuatro caminos que conducen hacia el río Maipo, dos denominados como Camino del Cerro las Cabras en amarillo, el Camino del Puente en rojo y el $\mathrm{Ca}$ mino Real del Bao en verde. Fuente: Carlos Torres Gandolfi (1994:4648) modificado por los autores. 


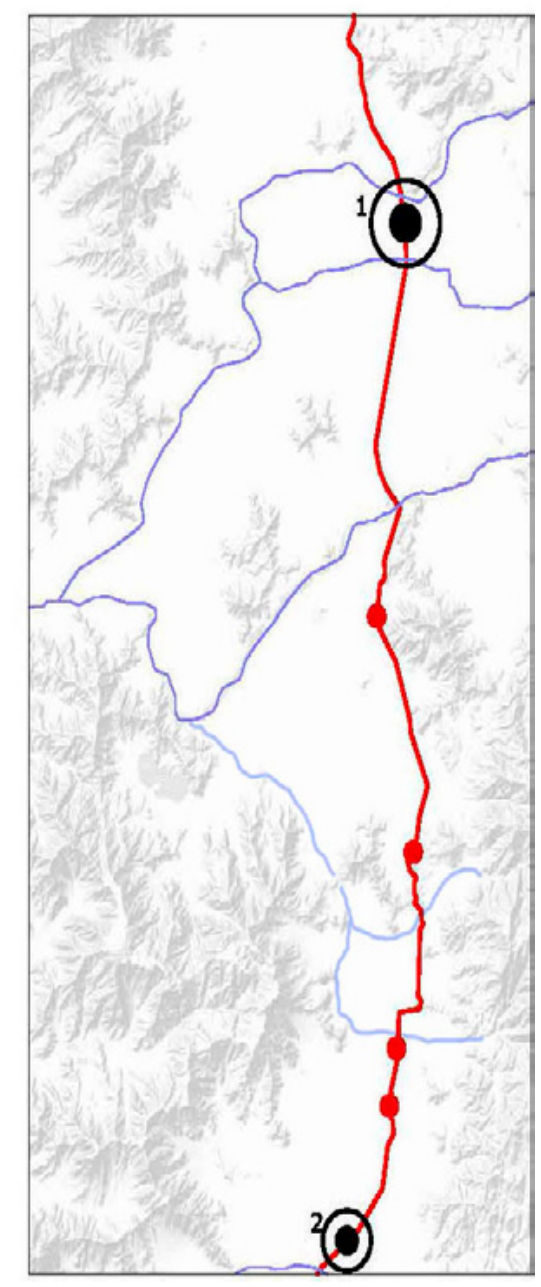

sur del río Maipo hacia los sitios agrícolas de Cerrillos de Chada, Cerro la Compañía y Hacienda Cauquenes, localizados valle de Aconcagua:

Cerrillos de Chada, ubicado en las cercanías de Angostura de Paine y sobre terrenos con gran capacidad agrícola [...] con ocupaciones Inka-Diaguitas no defensivas en su cima, asociado a un extenso asentamiento habitacional Aconcagua en el valle contiguo. [...] interpretado a partir de sus registros arqueológicos e históricos tempranos, como una suerte de guarnición o centro de abastecimiento de productos alimenticios y enseres [...] estratégicamente emplazado en la ruta de conquista [incaica] al sur, justo entre dos fortalezas o centros administrativos Inka (Chena y La Compañía) (Comisión de Trabajo Autónomo Mapuche, 2003:s/p).

Más adelante el mismo informe se refiere a los traslados, hacia fines del siglo XVIII, de los pueblos de indios de Chada y de las tierras agrícolas aledañas hacia el pueblo de Codegua, para su ocupación por parte de los hacendados (Plano Pissis, 1850, Figura 7 A). Desconocemos el punto de cruce del río por el cual el Camino Real de Chada conectaba los centros administrativos Inka de Chena y La Compañía evocados más arriba, sin embargo podemos arriesgar la tesis de que posteriormente -en la primera mitad del siglo XIX- éste podría haber sido conectado con el camino de Los Morros a través del puente del mismo nombre (Figura 3), volveremos a esto más abajo.

El segundo se refiere a que el camino Inca que ingresaba desde el norte hasta el centro fundacional de Santiago, estudiado por los mismos autores (Stehberg y Sotomayor
Figura 3. Trayectoria del antiguo camino entre Santiago (1) y Rancagua (2), que hacia 1850 conecta Santiago con antiguos poblados de Figueroa, Chada, Codegua y La Compañía, al sur del Río Maipo, probablemente a través del puente Los Morros. Elaboración autores. Fuente: Plano de Amadeo Pissis en 1850, Biblioteca Nacional. 


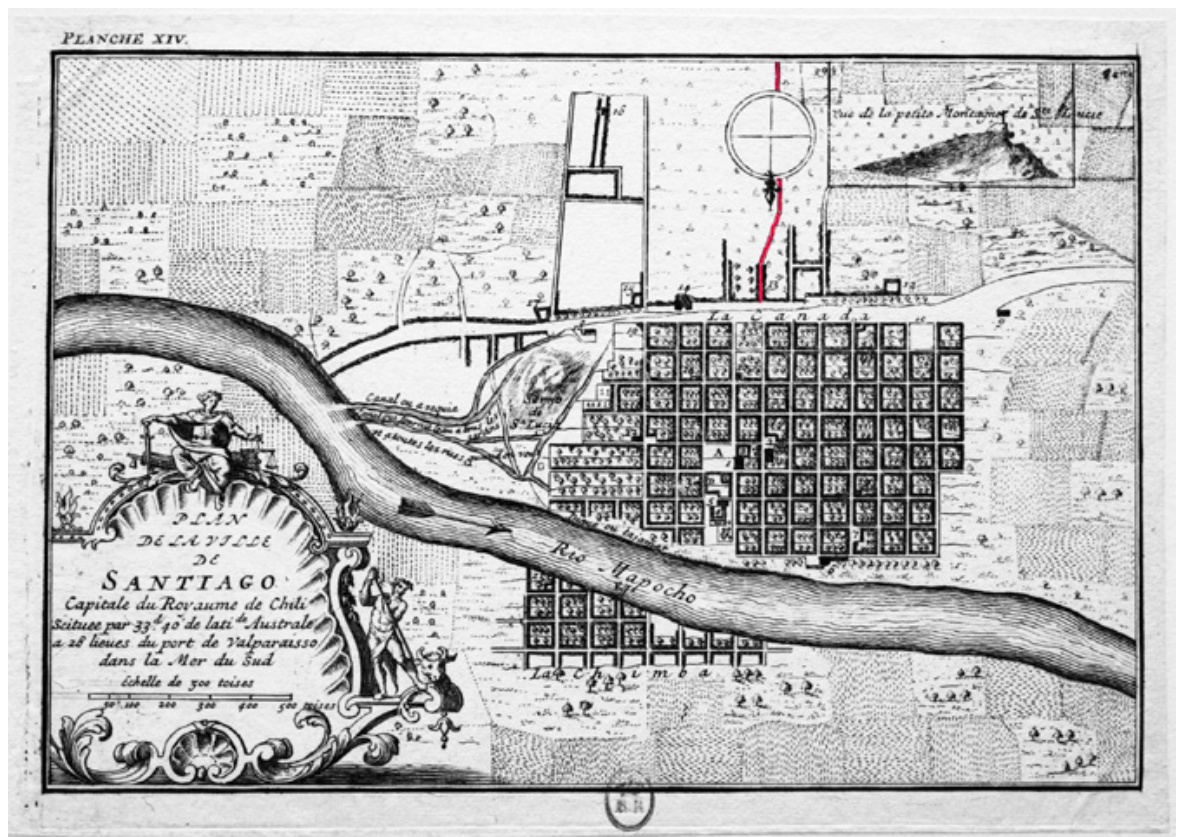

2012:108-109), se prolonga por el damero fundacional hacia La Cañada -actual Alameda Bernardo O'Higginis- hasta el punto donde nace el antiguo Camino de San Diego que según Correa (1984), se prolonga hacia al sur para adentrarse en los dominios del Llano:

[...] se extendían desde el brazo sur del río Mapocho [...] hasta el río Maipo y tomaban varias leguas por ambos lados del viejo Camino del Inca que, partiendo desde el río Mapocho, seguía por lo que es actualmente San Diego, Gran Avenida J M. Carrera y camino Los Morros, para continuar por éste hasta el río Maipo, cruzarlo y continuar hacia el sur. (Correa Benavides, 1984:16)

El plano de Amadeo Frezier, de 1716 (Figura 4) muestra la importancia el Camino de San Diego entre las vías que conducen desde el triángulo fundacional de Santiago hacia el sur, aunque no da cuenta de la distancia en que este se interna en el Llano, después de sortear el Zanjón de la Aguada, un curso de agua que corre de oriente a poniente por la cota más baja entre las cuencas del Mapocho y del Maipo. El tercer punto se refiere a las obras de ingeniería militar que se construyeron durante la Colonia para asegurar la conquista -fuertes, caminos y puentes-, y a las obras de ingeniería civil que se hicieron en tiempos de paz, entre las cuales Elías Arze en la "Revista de Ingeniería de la Construcción" nombra los "Puentes de Cal y Canto y Los Morros" como parte de los grandes proyectos de la época (1987:17). Nos queda por dilucidar el tramo de la ruta entre el Camino de San Diego y el río.

\section{0o - 1930. Camino agrícola en el valle fértil, poder público y renta de suelos}

En adelante según René León Echaíz en el Tomo II: "La República" de su "Historia de Santiago" (1975) el Llano de Lepe era recorrido por el primer tramo del Camino de la Frontera (1975:43), mismo al que se refiere Correa (1984) cuando describe la ruta que salía hacia el sur desde La Cañada (actual Alameda Bernardo O'Higgins) por el antiguo Camino de San Diego, para continuar con el nombre de Camino de la Frontera ${ }^{2}$. Transitaban por él las tropas que controlaban los territorios hasta la frontera con las tierras no conquistadas de los pueblos Mapuche. Es posible que después de cruzar el Zanjón
Figura 4. Plan de Santiago de chile, 1716. Amadeo Frezier. Muestra el Camino de San Diego -en rojo, interrumpido por ícono que indica el norte- como la huella principal de salida de Santiago hacia el sur. Fuente: Biblioteca Nacional de Chile.
2. La Frontera correspondía al límite sur de los territorios conquistados a los pueblos Mapuche, que en la Colonia llegaba hasta el río Maule y en la República fue extendido hasta el río BioBío. 

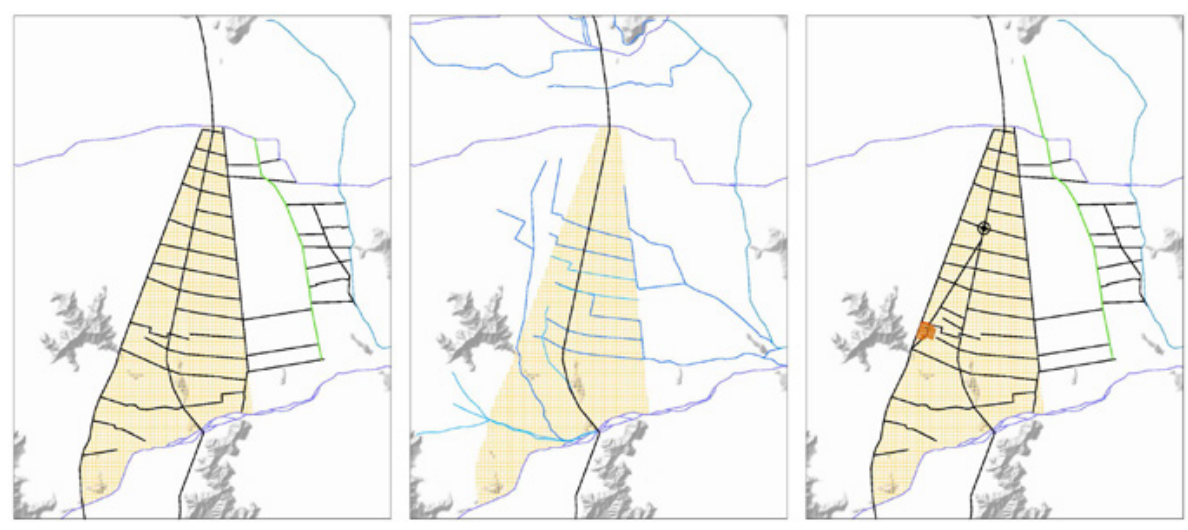

de la Aguada, este camino siguiera la ruta del antiguo Camino de Tango o del Vao mencionado más arriba, para cruzar el río por su zona menos profunda, el vado y continuar por una ruta más expedita hacia el sur. Mientras la ruta de los caminos agrícolas se mantenía usando los puentes coloniales, Puente Nuevo y Los Morros.

\section{Loteo del llano de lepe, primera operación inmobiliaria en suelo público}

La subdivisión del Llano de Lepe a partir de 1810 es particularmente importante para comprender el curso que tuvo el viejo camino de San Diego hacia el sur. Su destino durante este período está íntimamente ligado lo que podríamos calificar como un verdadera operación de gestión inmobiliaria liderada por los miembros del gobierno de la naciente República. En ella converge una serie de iniciativas puestas en marcha por la administración pública que dotarán de utilidad y valor a los suelos de esta propiedad. Podemos citar las siguientes: su subdivisión y la venta de predios agrícolas con ocasión de la inminente apertura del Canal San Carlos que permitirá dotarlos de agua; junto con ello, la fundación de la primera urbanización fuera de Santiago en la cuenca del Maipo, la Villa de San Bernardo, que ofrecerá residencia a las viudas de militares, y quintas de recreo a las familias adineradas de la ciudad, con lo cual se creará además, a proximidad de los predios agrícolas, un centro administrativo, comercial y de servicios; y la construcción del camino de "La Polvareda" para conectar la nueva villa con el camino de San Diego, y a través de este con Santiago, eje que pasará a llamarse Camino de San Bernardo (Figura 5).

Este proceso se inicia en 1801 con la venta de la propiedad de Lepe a Pedro Villar, un productor de vino que consigue plantar con gran éxito viñas en el extremo sur de su propiedad canalizando aguas del Maipo, con lo cual queda demostrado el potencial agrícola del Llano (Romero, 2016). A partir de allí esta extensión, que hasta ese momento servía escasamente para la crianza de ganado, se convertirá en un territorio apto para la explotación agrícola.

Cuenta René Echaíz (1975:44) que a su muerte, Villar deja su propiedad en donación a los pobres y al Hospital San Juan de Dios. Siendo ésta una institución religiosa de beneficencia, el gobierno patriota le solicita que reciba a los militares heridos de las guerras de Independencia, al mismo tiempo le impone una administración nombrada por el propio Director Supremo O'Higgins (Echaíz, 1975:37). De este modo, las tierras del Llano quedan de facto bajo tutela del gobierno. Las narraciones de Echaíz muestran bien cómo éste da impulso a su subdivisión y venta:

Durante el Gobierno de don Bernardo O'Higgins, se acordó vender estas tierras. Por acuerdo del Senado Consulto de 9 de Enero de 1819 se vendieron cuatro mil cuadras a don Fernando Errázuriz [...]. Y por acuerdo del 9 de Febrero de 1821, se acordó lotear el resto y venderlo en pública subasta. [...] En virtud del último de estos acuerdos, el Llano del Maipo fue dividido en hijuelas de diez cuadras por lado; y cada

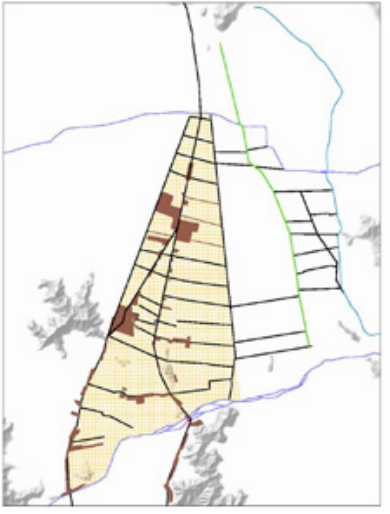

Figura 5. Operaciones en el Llano de Lepe. De izquierda a derecha: loteo del Llano de Lepe 1821; canalización de aguas del Maipo 1826; bifurcación camino La Polvareda y creación de la Villa San Bernardo 1821; tranvía y creación de nuevos loteos La Cisterna 1901. En el centro de cada imagen se encuentra el trazado del Camino de Los Morros. Fuente: Elaboración autores. 

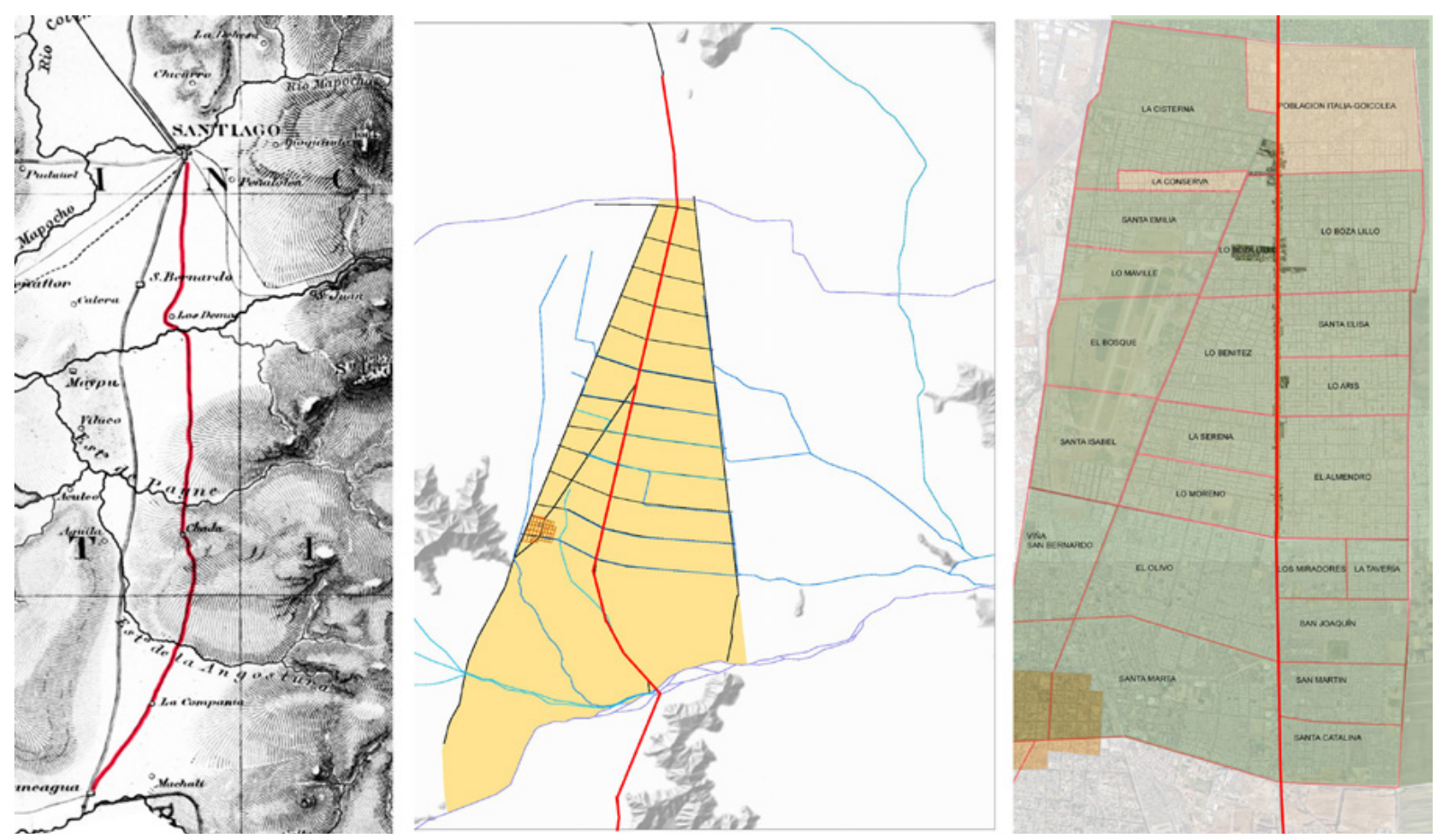

una de ellas se dividió, a su vez, en lotes de cinco cuadras por lado. A cada lote se le asignaron derechos de aguas del canal San Carlos en construcción. (Echaíz, 1975:44)

Es interesante observar la racionalidad de la subdivisión predial del Llano de Lepe. Ésta se define sobre la base de superficies aptas para la explotación agrícola, que a su vez son divisibles en cuadras de dimensiones urbanas. Es así como la superficie total se subdivide regularmente de norte a sur en tramos de $1,28 \mathrm{~km}$ y de oriente a poniente, en tramos de dimensiones variables, dando lugar a predios agrícolas divisibles en cuadras de $128 \mathrm{~m}$ por lado, medida que corresponde a las manzanas del área urbana de Santiago colonial ${ }^{3}$. Se establece así un patrón regular de división de suelo que servirá de base para el trazado de la canalización de las aguas, y a su vez para el trazado de la trama viaria principal en el sentido oriente-poniente. Con ello se sientan las bases para un proceso de urbanización posterior cuyos ejes principales perduran hasta hoy entre calle Carlos Valdovinos por el norte y Av. Mariscal en los confines de la ciudad por el sur (Figura 6 B).

No contamos con planos que muestren los trazados de la división narrada más arriba por Echaíz, sin embargo la subdivisión de las chacras, que persiste hasta 1910 (Figura 6 C) corresponde bastante bien con geometría del loteo del Llano acordado en el Senado en 1819, en cuyo eje central se observa el trazado del camino de Los Morros. Además, en el plano topográfico de la cuenca de Santiago elaborado por Amadeo Pissis en 1850 (Figura 6 A) se observan los trazados del Camino de San Bernardo y del antiguo camino hacia los poblados agrícolas del sur, posiblemente camino de Los Morros.

\section{Fundación de San Bernardo}

La subdivisión del Llano y la apertura del Canal San Carlos convergen en la propuesta de Domingo Eyzaguirre de crear una villa en el Llano, "la cual se sustentaría en principio con los fondos reunidos por la venta de aguas del Canal San Carlos y de los terrenos regados por él" (Romero, 2016:9). Por acuerdo del Senado de 1821 se decide reservar primero treinta y seis, y luego doscientas cuadras para la creación de un núcleo residencial, administrativo, comercial y de servicios También se dispuso
Figura 6. A: Mapa Provincia Santiago, 1855, autor Amadeo Pissis. En color se destaca camino entre Santiago y Rancagua a través de Los Morros. B: Estructura predial y canales del Llano de Lepe en 1821. Muestra la subdivisión del llano en 11 módulos de $1,28 \mathrm{~km}$, entre calle Carlos Valdovinos por el norte y el Canal San Bernardo por el sur. C: Detalle de chacras existentes en 1910 en torno al Camino Los Morros, basadas en la subdivisión mencionada (módulos 5 a 10). Fuentes: A. Gilliss, J. (1855). The U.S. naval astronomical expedition to the southern hemisphere, during the years 1849-'50-'51-'52. Vol. I; B. Elaboración autores; C: Modificación autores sobre Plano IGM 1910.

3. A partir de registros planimétricos del levantamiento de calles de 1890 de Alejandro Bertrand, hemos corroborado que en promedio la medida de la cuadra, de eje a eje de calle, en la Plaza de Armas de Santiago, es de 127,7m. 
en este acuerdo que se diese prioridad en los sitios reservados para la villa a los militares y las viudas de los defensores de la patria (Echaíz, 1975). Incluso, con el fin de crear trabajo local se decretó que sólo allí se podrían fabricar los uniformes del Ejército (Romero, 2016). Este sería el primer proyecto de urbanización en el valle fuera de la ciudad de Santiago.

Domingo Eyzaguirre fue designado Superintendente de las obras, quien bajo la dirección de Bernardo O'Higgins trazó la Villa San Bernardo, nombrada así en homenaje a Bernardo O'Higgins. Nueve años después, en 1930 la Villa era inaugurada y don Domingo Eyzaguirre era dueño de una propiedad (Echaíz, 1975:45). Finalmente, con la República ya establecida, en 1834 se crean seis Departamentos en la Provincia de Santiago. San Bernardo es nombrado cabecera del Departamento de La Victoria y Eyzaguirre su Gobernador.

Para acelerar la venta de propiedades en San Bernardo el mismo Eyzaguirre propone una ley que permita otorgar créditos a los compradores. El resultado de estas operaciones es una progresiva alza de los valores de suelo. Según Romero: "las cuadras pasan de un valor de $\$ 8$ en 1822 a $\$ 100$ en 1840 y a $\$ 400$ en 1860" (2016:9, extraído de Guía Patrimonial de San Bernardo). De hecho en cuanto los sitios contaron con agua, se aceleró la compra de terrenos urbanos y agrícolas. Con el tiempo vinieron a establecerse grupos de extranjeros (Echaíz, 1975) y a partir de la llegada del ferrocarril del sur en 1857, con una estación en San Bernardo, éste se convertirá en uno de los balnearios favoritos de la oligarquía santiaguina (Romero, 2016:9). Hacia mediados de siglo San Bernardo contaba cerca de 10.000 habitantes.

\section{Bifurcación hacia San Bernardo, el Camino del Sur}

Un factor esencial para el éxito de esta operación era contar con una conectividad fácil a Santiago. Se traza y abre entonces un camino de bifurcación del Camino de la Frontera desde la altura del poblado de La Cisterna hasta la calle principal de San Bernardo, Av. Eyzaguirre que conduce a su plaza central. A este camino conocido como de la Polvareda Correa lo describe como "[...] un camino angosto de tierra, con mucho polvo en el verano y grandes barriales en invierno [...]" (1975:18). Este, en conjunto con el tramo del Camino de La Frontera al norte de La Cisterna pasará a ser nombrado como Camino de San Bernardo. Su tráfico cobra tal importancia que hacia mediados de siglo se congestiona con el paso incesante de las carretas que transportan mercaderías entre el campo, San Bernardo, el Mercado de San Diego y el Matadero, localizados en torno al Camino de San Diego en el límite de Santiago con el Zanjón de la Aguada. A esto se suma el tráfico de carretas que en fines de semana conducen a las grandes familias a sus segundas residencias y a sus casas quinta en la Villa o en los campos y viñas aledañas.

Otro hecho importante, que explica la jerarquía que cobró el Camino de San Bernardo, es la prolongación de su trazado hasta entroncar con el Camino del Sur -probablemente posterior avenida Ochagavía- a los pies del cerro Chena cuya ruta, menos accidentada que la del camino por Los Morros hacia el sur, se transformaba en la vía más directa de salida de la ciudad (Figuras 5 y 6 ). Estos hechos provocaron que el tramo del antiguo camino -Los Morros- comprendido entre La Cisterna y el río Maipo, fuera perdiendo importancia y pasará a ser la espalda de la creciente actividad urbana del de San Bernardo, para mantenerse por más de un siglo como camino agrícola.

\section{El Canal San Carlos y la factibilidad de aguas para la explotación agrícola}

La posibilidad de explotar las tierras de secano del Llano de Lepe dependía de la dotación de agua. La construcción de un canal que condujera las aguas del Maipo hacia el Mapocho y a lo largo de su camino permitiera conducir aguas pendiente 


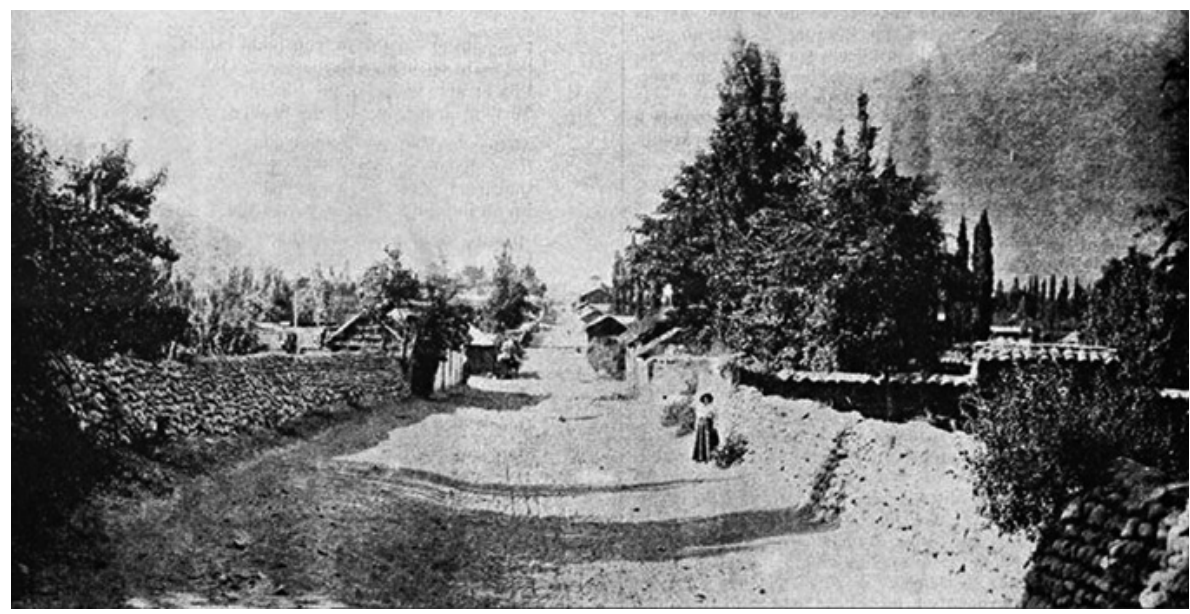

abajo hacia las tierras del Llano, el Canal San Carlos, había sido desde 1713 una de las preocupaciones principales de la autoridades de la Colonia. Tras casi un siglo de intentos interrumpidos por las crecidas de las aguas y la falta de financiamiento, en marzo de 1819 el Senado propone varias medidas para terminar las obras. Entre ellas, la venta de los terrenos del llano y de los derechos de agua, con la finalidad de recaudar fondos para financiar dichas obras y crear la nueva Villa. Las obras fueron concluidas en 1821 bajo la dirección de Domingo Eyzaguirre, Intendente del Canal (Correa, 1984:62), sin embargo éste será puesto en marcha en 1826. Año en que el mismo Domingo Eyzaguirre propone que su administración y mantención pase a manos del sector privado, "al año siguiente [...] el Gobierno emite decreto cediendo todos sus derechos sobre el canal en favor de los propietarios particulares del Canal. [...] A los dos meses siguientes, [...] se celebra la reunión para formar la sociedad" (Correa, 1984:63).

Se canalizan así las aguas del río Maipo desde la bocatoma del Canal San Carlos hasta el Camino del Puente, costado oriente del predio del Llano de Lepe. Desde allí se distribuyen por una serie de canales paralelos que recorren de oriente a poniente, desde el Camino del Puente -hoy avenida Santa Rosa- hasta el Camino del Tango -Ochagavía- a lo largo de los límites de los predios agrícolas, siguiendo el sentido de la pendiente y atravesando el camino Los Morros. Hacia 1840, estos canales darán lugar a la formación de calles configurando una macro trama vial que será estructurante de los procesos de urbanización posteriores. En el plano de 1910 (Figura 6B) se observan cinco vías con canales que cruzan el camino Los Morros, las que se conservan hasta hoy como calles y avenidas: Av. Américo Vespucio, calle Juan Solar Parra, Av. Observatorio, Av. Lo Martínez y Av. Lo Blanco.

Así las propiedades del Llano cobran rentabilidad, tanto por su potencial agrícola, como por el alza de los valores del suelo que de ello se desprende. Se planta en ellas viñas, árboles frutales y hortalizas además de las arboledas que las limitaban ya sea con el camino, ya sea entre ellas. El regadío convirtió en un vergel esta vasta extensión, transformando con ello el clima de la ciudad que recibía el fresco de las plantaciones con los vientos provenientes del sur poniente (De Ramón, 2000:122). También el camino Los Morros comienza a cambiar de aspecto. Las propiedades agrícolas comienzan a construir sus edificaciones a lo largo de sus frentes, a la manera de los pueblos calle larga de los campos de los valles centrales (Figura 7).

Antes de 1800, los mapas muestran una estructura de caminos en que no aparece el de Los Morros. En los mapas de 1850 en adelante (Figura 7) ya aparece el Camino de Los Morros como uno de los ejes estructurantes de salida hacia el sur junto con el Camino
Figura 7. Típico camino rural del Chile del siglo XIX. Fuente: Memoria Chilena. 


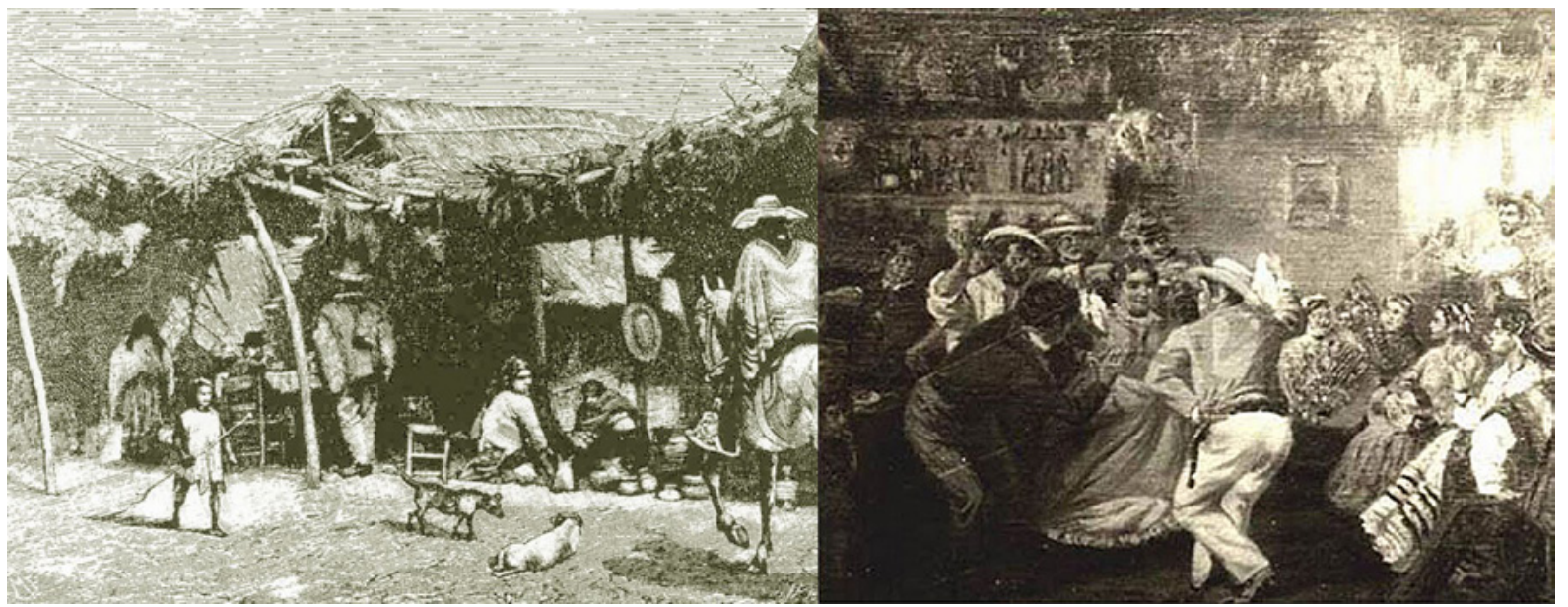

de San Bernardo que entronca con el posible Camino de La Frontera. Por su parte, el trazado del loteo del Llano de Lepe, que data de 1821 ya muestra en su eje un camino que prolonga el camino de San Diego en línea recta hacia el sur y divide los predios agrícolas en coherencia con el loteo resultante de los acuerdos del Senado Consulto del 9 de Enero de 1819, reportado por Echaíz más arriba. Al mismo tiempo, los trazados de las aguas provenientes del Canal San Carlos, que datan de 1821-1826 ya revelan la presencia del camino en el eje del Llano de Lepe. Esto nos permite arriesgar la tesis de que el Camino Los Morros puede haber sido parte de dicho loteo, permitiendo conectar estas tierras con el río del Puente Los Morros para empalmar con el antiguo Camino de Chada, con fines prioritariamente agrícolas.

Transitaban por estos caminos caballos y carretas transportando mercancías desde y hacia Santiago, atravesando las tierras secas y pedregosas del Llano del Maipo, haciendo pausa para descansar en algunos caseríos que se levantaban en su entorno donde habitaban los sin tierra y sin trabajo.

El Valle del Maipo o de Lepe como lo llamaron en tiempos de la Colonia, estaba poblado por una infinidad de rucas miserables. La región era estéril e inhóspita y los documentos de la época la calificaron como "Cascajal". Sólo crecían en ella unos que otros matorrales y pequeños grupos de espinos o algarrobos. (Correa Benavides, 1984:16-17)

En estos puntos de pausa de los viajeros, se levantaban las chinganas (Figura 8), donde se juntaban quienes vagabundeaban por el valle, para hacer la fiesta, tomar y bailar, lugares que subsistían de la venta de comida y alojamiento, donde las mujeres solas acogían a los viajeros de todo tipo (Figura 8). Para el historiador Gabriel Salazar, éstas fueron espacios donde se gestaron las identidades populares: "En torno al rancho y la ramada, en torno al lugar productivo de la mujer campesina, se fue tejiendo una red social popular. Un espacio de autoidentificación y reconocimiento del bajo pueblo" (Salazar, 1992:72). El artículo "Chinganas" publicado por la Biblioteca Nacional de Chile (s/f:s/p) recoge los dichos de este autor: "La chingana era un abierto y hospitalario hogar para la gran masa de 'rotos' que deambulaba por el territorio buscando mejores perspectivas, escapando de la justicia o de las levas militares." Estos lugares de fiestas populares fueron muy combatidos, tanto durante la Colonia como en la República. Las autoridades y los citadinos los consideraban como "lupanares o escuelas de todos los vicios" (Echaíz 1975:25). En reiteradas ocasiones se daba órdenes públicas de prohibirlas. Un punto de pausa obligada en el camino hacia el sur se encontraba a la altura de Lo Ovalle en la Actual Gran Avenida, que pasó a ser un lugar reconocido de recreación, bebida y juego en el siglo XIX.
Figura 8. A: Lugares de descanso a lo largo de los caminos en tiempos de la Colonia. Autor anónimo. B: Chingana, lugares de fiesta popular fuera de Santiago que perduraron hasta fines del siglo XIX. Autor Manuel Antonio Caro. Fuente: Colección Biblioteca Nacional de Chile. 


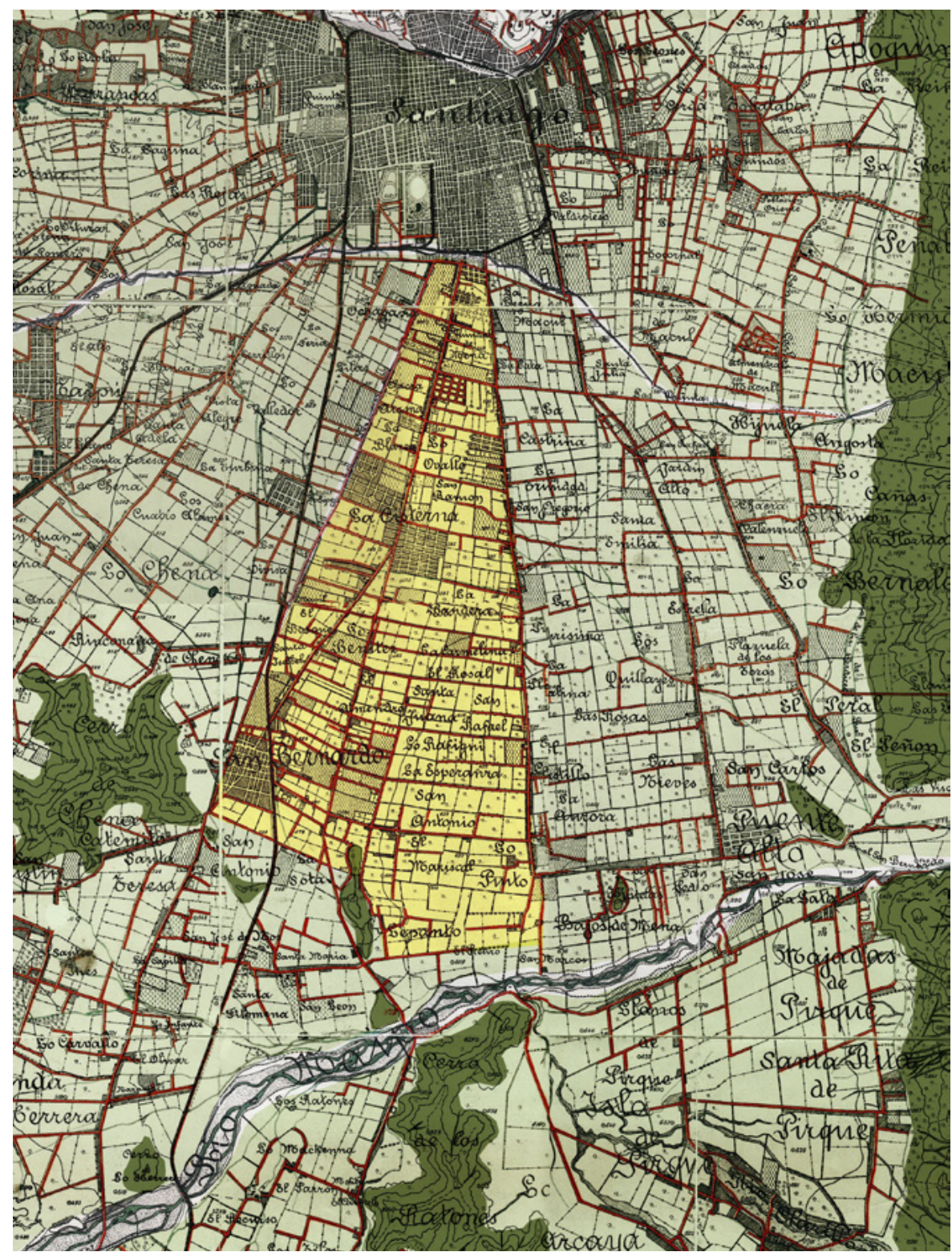

\section{El tranvía y el loteamiento residencial del Llano}

Un factor que impulsa la urbanización en el Llano es la implementación del tranvía. Uno de los recorridos importantes de tranvías en Santiago fue el que circulaba por San Diego y el camino de San Bernardo, llegando primero hasta la Cisterna y después hasta la plaza de San Bernardo en 1901. Ya desde 1906, este recorrido de carros tirados a sangre fue uno de los primeros en contar con carros eléctricos. Debido a su localización privilegiada, el antiguo poblado de La Cisterna, situado al poniente del punto de la bifurcación del Camino de San Bernardo, se desarrolla a principios de siglo como un centro dotado de comercio y servicios como escuelas, restaurantes, casino, sala de filarmónica, para las chacras de grandes personalidades localizadas en el entorno (Correa, 1984).

Esta nueva accesibilidad, dotada de mayor confort y menores tiempos de viaje, incentiva la creación de varios loteos residenciales para grupos acomodados en los predios del Llano. Hacia 1910 se crean los primeros loteos residenciales próximos a la Cisterna. Es así como en torno al Camino de San Bernardo, a proximidad de La Cisterna, se crean las primeras
Figura 9. Provincia de Santiago,1910 ca., Escala 1:100.000. Autor: Estado Mayor General del Ejército de Chile, Departamento de la Carta. Reproducción provisoria (fragmento Santiago sur), coloreado por los autores para destacar el área del Llano de Lepe (amarillo). Se observan en el punto de bifurcación los nuevos loteos residenciales y al sur, San Bernardo. También se observan los puntos de cruce de los caminos con el río Maipo. Fuente: Instituto Geográfico Militar de Chile. 


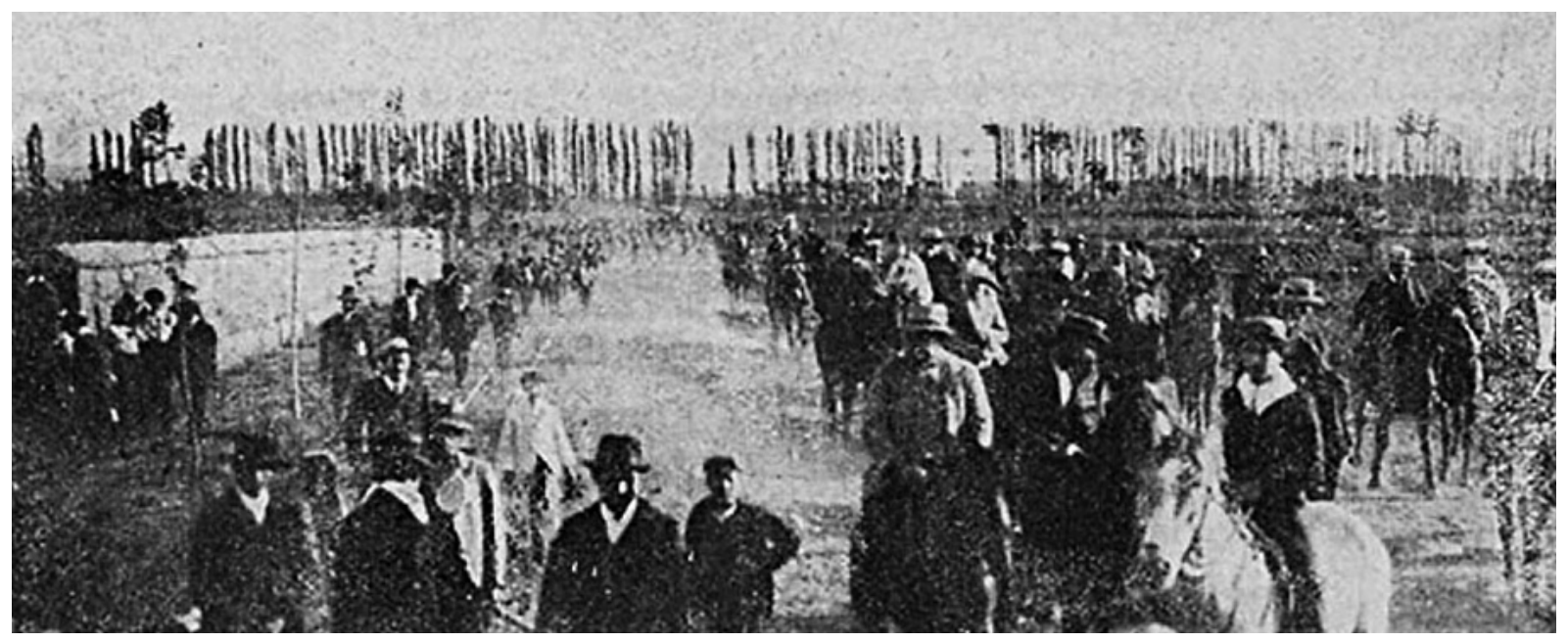

poblaciones: Villa Italia, Biaut, Nueva España y Goycolea. Muchos de ellos, implementan sus propias líneas de tranvía para garantizar su accesibilidad desde y hacia Santiago.

Una de las primeras es la Población Villa Italia que ofrece como atributos su localización privilegiada, su conectividad con Santiago y la cercanía a los servicios de La Cisterna (Figura 10). Su documento publicitario señala que se "ofrece a todo el mundo [...] la mejor oportunidad para hacer especulaciones, invertir sus ahorros [...] con la absoluta seguridad de la garantía del dinero invertido y que duplica en breve de valor" (S/a, 1910:9). Más adelante el documento señala que su localización también garantiza buenos vecinos futuros ya que en el entorno se encuentran en formación una serie de Villas destinadas a familias acomodadas y a extranjeros, inmigrantes técnicos, “[...] dueños, socios principales o empleados en las industrias que se habían establecido en la ciudad desde la segunda mitad del siglo XIX” (De Ramón, 2000:207)

Además de los loteos privados, en torno al Camino de San Bernardo se localizan algunas instituciones públicas. En 1911 entra en funcionamiento en un predio de gran superficie localizado a proximidad de la Villa al costado poniente de la vía, el Observatorio Astronómico Nacional. En 1913 se crea en el mismo predio, la Escuela de Aeronáutica Militar que irá creciendo hasta pasar a ser en 1936 la Base Aérea de El Bosque.

Es sorprendente observar la velocidad de los cambios en el transporte ocurridos en el primer cuarto del siglo XX. A mediados de los años 20 se introducen los vehículos motorizados en Santiago, el automóvil pasará a ser preferido por las familias santiaguinas para salir los fines de semana y días festivos a sus casas de campo, viñas o casas quinta. A su vez los autobuses comienzan a transportar a los residentes de las villas que trabajan en el centro. La superposición de medios de transporte hace imposible la circulación entre San Bernardo y Santiago. En 1926 el Camino de La Polvareda está entre de los primeros en ser ensanchados y pavimentados, con dos sentidos de seis metros cada uno y veredas de tres metros a cada lado. Esta flamante vía, aclamada como una de las más modernas de la Provincia, dejará de llamarse Camino de San Bernardo o de la Polvareda y se pasará a llamar Gran Vía (Errázuriz, 2014).

Se profundizan así las diferencias entre la Gran Vía y el camino Los Morros. De aquí en adelante este último quedará definitivamente en la trastienda del desarrollo moderno de la ciudad, mantendrá por largo tiempo su carácter de camino rural conformado en su costado poniente por los fondos de los predios que enfrentan la Gran Vía, y en su costado oriente, por las casas e instalaciones de los predios que mantienen su función agrícola. No será sino hasta 1940 que los predios de su entorno comenzarán a poblarse por proyectos de habitación popular y operaciones de vivienda social.
Figura 10. Fotografía de la inauguración de la Población Villa Italia, en la bifurcación entre camino San Diego y Camino a San Bernardo. Fuente: Harvard University - Collection Development Department, Widener Library, HCL / Población Villa Italia, La Cisterna, mayo de 1910. Santiago (Chile): Impr. Barcelona, 1910. 


\section{0 - 1990. Los Morros, de camino a avenida}

A principios del siglo XX, Santiago cuenta cerca de 350.000 habitantes, cifra que se duplica hacia 1930 (De Ramón, 1985). Junto con ello, el área urbana crece exponencialmente en baja densidad, aparecen de la noche a la mañana las poblaciones Callampa conocidas con este nombre por su espontánea aparición en los bordes de la ciudad. En el Llano se subdividen los predios agrícolas y se inicia la creación de loteos para construir villas fuera de la ciudad.

\section{De camino rural a avenida periférica}

A partir de los años 30 Santiago conoce un crecimiento explosivo, tanto en población como en superficie. La crisis del salitre y la crisis internacional que pilló al país endeudado, una fuerte contracción del empleo en la minería, la agricultura, la construcción y la administración pública, repercutieron en la concentración de población en las ciudades y en particular en Santiago. Al ritmo del empobrecimiento de la población, las migraciones de desocupados de las minas y el campo hacia la ciudad, las carestía de vivienda, los movimientos sociales y las políticas públicas que intentan hacerles frente, el camino Los Morros pasará de ser un camino rural a una calle de la periferia pobre. A partir de los años 40 va acogiendo en su entorno poblaciones de vivienda social. En un principio son conjuntos para empleados, trabajadores, obreros y miembros de las fuerzas armadas, que enfrentan la Gran Vía y dan espalda a Los Morros. Desde los años 60 en adelante, serán poblaciones de familias en extrema pobreza que por esfuerzo propio irán construyendo allí su lugar.

En torno al tramo de estudio del camino Los Morros -que comprende una extensión de 5 kilómetros entre la bifurcación de la Gran Vía por el norte y la localización actual del hospital el Pino por el sur- se construyen 21 barrios a partir de distintas iniciativas y en el marco de distintas políticas habitacionales entre 1930 y 1990. Sin embargo, el modelo de urbanización por loteos que se aplica en este período y su implantación discontinua en el tiempo, no favorecerán la configuración del camino como una avenida principal, no obstante el papel que éste cumple como eje organizador de la implantación de dichas urbanizaciones. Por el contrario, en la medida que sus diseños focalizan sus espacios públicos hacia el interior, profundizan su condición de límite entre barrios que le dan la espalda.

\section{0-1950}

En 1931 el Estado crea el Plan Nacional de Viviendas asociado a la Ley de Fomento de la Edificación Obrera. Una de sus líneas fomenta, a través de la Junta Central de Habitación Popular y la Caja de Crédito Hipotecario, "la compraventa de sitios a plazo [que] correspondió a loteos que se generaron en las periferias de la ciudad y fueron puestos en el mercado por los mismos propietarios [...]" (Hidalgo, 2005:145). Según Hidalgo, este marco institucional da lugar a la creación de aproximadamente 115 loteos con casi 6500 beneficiarios en las comunas de la periferia, entre los cuales 36 se encuentran en las comunas del Llano (2005:154-155). Sin embargo, si bien permite lotear y vender suelo, no logra construir las viviendas necesarias para acoger las olas de migrantes que llegaban a Santiago, a cambio impulsa una flameante alza de los valores de suelo.

Entre 1936 y 1941, se crea una nueva institucionalidad focalizada en el financiamiento con aportes fiscales y fondos del seguro obligatorio, administrados por las Cajas de Habitación y de Previsión, para la construcción de vivienda orientada a empleados y trabajadores.

Desde 1940 se observa en el entorno del camino Los Morros, una serie de villas creadas por instituciones públicas, Cajas de Previsión y Cooperativas. En primer lugar se 

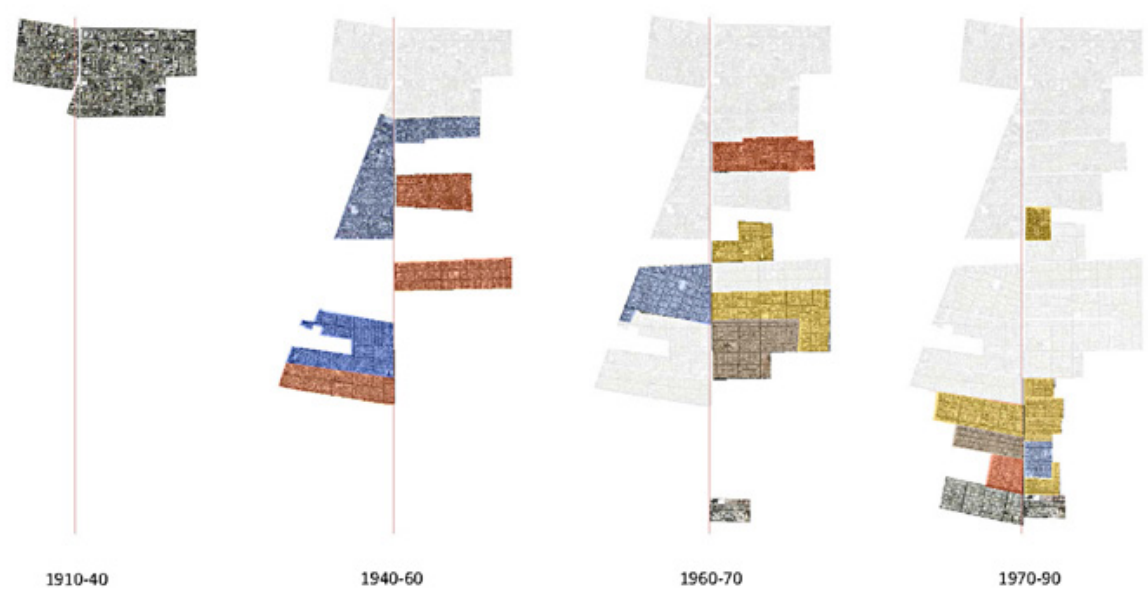

Figura 11. 1910-1990, Secuencia del proceso de urbanización en torno a Los Morros en el tramo de estudio. Tipos de operación: compraventa de sitio con edificación (azul fuerte), compraventa de sitio y edificación por iniciativa propia (azul), loteo y edificación por cooperativa (rojo), políticas públicas de vivienda social (amarillo), tomas de terreno (beige). Fuente: Elaboración autores.

construye frente a la Base de la fuerza aérea, un conjunto habitacional destinado a los miembros de la institución que contempla loteo, urbanización y edificación: la villa Cóndores de Chile. Ésta abre su frente hacia la Gran Vía dando la espalda al camino Los Morros. Junto con ella, se al norte del camino Los Morros, en el límite sur de Villa Italia y a ambos costados del camino Los Morros, se crean otros dos conjuntos de vivienda destinada a la compra por financiamiento propio, para miembros y empleados de la misma institución: las poblaciones Carlos Castro y Sargento Aldea (Figura 11).

En este mismo tiempo, se construyen tres poblaciones por cooperativa. Por el costado oriente, la Villa E.T.C. destinada a los trabajadores de la Empresa de Transportes Colectivos y la Población el Sauce. Hacia el sur por el mismo costado, la Villa el Esfuerzo (Garcés, 2000). El tamaño de los sitios da cuenta de sus orígenes cooperativos y del estatus de sus propietarios: obreros y trabajadores públicos o privados (Figura 11).

En contraste con la Gran Vía que se consolida como avenida jerárquica, pavimentada y dotada de diversos modos de transporte público, el camino Los Morros conserva todavía su condición rural, sin pavimentación ni dotación de transporte público. Entre ambas, los antiguos caminos transversales -algunos todavía con canales- cobran importancia para dar accesibilidad hacia la ciudad a quienes habitan en torno a los Morros. En este periodo el avance de las poblaciones hacia el sur llega hasta la actual Avenida Lo Martínez, aunque sin continuidad. Las poblaciones se levantan en predios aislados, distantes entre sí por 600 a 800 metros (Figura 11). El costado oriente del camino no cuenta más de $812 \mathrm{~m}$ bordeados por vivienda, mientras el poniente cuenta $2.100 \mathrm{~m}$.

$1950-1973$

En la década de los 50 el problema de la vivienda entra en una fase crítica para instalarse en la escena política del país. El fomento de la industrialización y la minería enfrenta sus primeras crisis, el desempleo y el alza del costo de la vida se sienten en las ciudades, las migraciones aumentan. Proliferan las callampas, ocupaciones espontáneas de las franjas fiscales localizadas en los bordes de cursos de agua y de las grandes vías de circulación, o en cualquier intersticio no cautelado. Emergen los movimientos sociales y comienzan a expresarse, primero a través de organizaciones sindicales y estudiantiles, y después a través de organizaciones de pobladores no asalariados. Hacia fines de la década "se produjeron numerosas huelgas y asonadas populares [...] paros nacionales, que tuvieron gran aceptación en la población del país" (Hidalgo, 2005:186).

Cada vez más organizadas, en los años 60 estas ocupaciones pasarán a ser tomas de terreno emprendidas como actos políticos que poco a poco irán creando vínculos con 
los partidos. La primera toma de terreno se lleva a cabo en 1947 (Población La Victoria). Entre 1968 y 1970 se organizaron más de 200 tomas, las cuales dieron origen a campamentos que perduraron hasta hace una década.

En 1957 el gobierno firma con Estados Unidos un Convenio Básico de Cooperación Técnica a partir del cual se propiciará la solución de los problemas habitacionales para los más pobres incorporando el esfuerzo propio y la ayuda mutua, para reducir los costos de construcción. Es así como se crea el Programa de Autoconstrucción y Ayuda Mutua y en 1959 se crea un nuevo Plan Habitacional. Pero es a partir de 1964 cuando la autoconstrucción entra en pleno vigor, a través del Programa Operación sitio, asociado a un Plan de Ahorro Popular o por medio de Cooperativas. Estos programas son dirigidos a familias en extrema pobreza radicadas en poblaciones callampa o en campamentos resultantes de tomas de terreno. A través de ellos se entrega un sitio con mínima urbanización, letrina y una construcción ligera de dos cuartos. La consolidación de la vivienda debía hacerse por autoconstrucción.

En los años 60 se construye en el costado poniente de la Gran Vía uno de los últimos conjuntos habitacionales por compraventa privada, La Población Luis Martínez cuyo fondo colinda con el Camino Los Morros. Más adelante se levantan en el costado oriente del camino Los Morros cuatro poblaciones destinadas familias en extrema pobreza, radicadas a través del Programa de Operaciones Sitio (Garcés, 2000): la Población Yolanda Díaz construida por Cooperativa, la Villa La Cisterna y la Población Santa Elena, erradicadas de campamentos originados por tomas en otros lugares de la ciudad, y la Población Los Acacios, originada por una toma de terreno en el mismo lugar (Garcés, 2000).

Nosotros llegamos, yo creo que, a fines del 69, porque cuando salió Allende en el 70 ya estábamos aquí [...] ¿isabe más o menos de cuando son estas poblaciones? Éstas, del 64. Tu papá nació el año 60 y él llegó de 4 años aquí po', y ellos venían de una toma, la mayoría vienen de otras tomas [...] claro, debió haber ocurrido algo importante en el año 64, que quisieron despejar la vías donde ellos estaban, no sé qué sucedió, entonces los trajeron [...] a todas las gentes de los campamentos los trajeron para acá, y ellos vivían allá en Santa Adriana, Santa Olga, todos esos lados, para que no hubieran tantas tomas, les dieron estos terrenos [...] (Entrevista a María Arias, realizada el 6 de octubre de 2004, extraída de Muñoz Arias, 2004:5).

Si los años 60, a fines del gobierno Liberal de Alessandri y durante el gobierno Demócrata Cristiano de Frei, fueron los de acceso a suelo a través de dotación de sitios con servicios y autoconstrucción, entre 70 y 73 el gobierno de Allende afirma la vivienda como un derecho a ser provisto por el Estado, y de un giro hacia la provisión de vivienda terminada, dotada de urbanización, equipamiento público y buena localización. Se implementan así nuevos programas de construcción y consolidación de viviendas y barrios.

En este tiempo [1969] había luz y agua, no alcantarillado, estaban rompiendo las calles para ponerlo, ni calles pavimentadas, habían muy pocas, teníamos pozos negros y ahí como el año 73 hicieron alcantarillado, definitivamente hicieron esta población, estas casas (Entrevista a María Arias, 18 de noviembre de 2004, extraída de Muñoz Arias, 2004: 6).

Sin embargo, pese a la construcción masiva de viviendas, las tomas de terreno aumentan en este período como bandera de lucha social en el ámbito urbano, incrementando la acumulación del déficit habitacional en lugar de reducirlo como era su objetivo.

Entre 1960 y 1973, persisten en buena parte las características del camino Los Morros, mitad rural, mitad urbano, pese a la cantidad de población que se emplaza en su torno "[...] ahí para allá eso era peladero, era duraznal" (Muñoz Arias, 2004:6). No hay datos 
de dotación de transporte público en él, aunque a 1,5 km hacia el sur de las poblaciones existentes se localiza el Hospital El Pino, en terrenos de un antiguo sanatorio. Se mantiene en sus bordes la alternancia de frentes de poblaciones con predios rurales. De los 5,3 km que atraviesan la actual comuna de El Bosque, el borde oriente se encuentra más consolidado con un frente urbano fragmentado de $1.550 \mathrm{~m}$, mientras el poniente alcanza un frente de $650 \mathrm{~m}$.

\section{$1973-1990$}

En el periodo de la Dictadura Militar cambia el enfoque de la política de Vivienda. En adelante se entenderá no como un derecho, sino como un bien que se obtiene a través del trabajo y el ahorro. Desde 1980 la Junta lanza la Política de Subsidio Habitacional, según la cual el Estado delega la construcción de la vivienda al sector privado y toma para sí la tarea de subsidiar su compra a través de un sistema mixto compuesto por un aporte estatal y un préstamo bancario al futuro propietario. De este modo incorpora la participación privada en la dotación de suelo y la construcción. Así, el Programa de Subsidio Habitacional entrega viviendas cuyas características dependen de la capacidad de ahorro de la familia, entre los cuales el Programa de Vivienda Básica que contempla operaciones en base a sitios de $100 \mathrm{~m}^{2}$ y una superficie construida de $24 \mathrm{~m}^{2}$ con estándares reducidos de calidad y sin equipamientos públicos, está destinado a las familias en extrema pobreza.

En 1981, se decreta la subdivisión comunal a través de la cual se asignará a las comunas atribuciones en vivienda entre otras. En este momento nace la Municipalidad de El Bosque que entrará en funciones en 1992.

Dado que las tomas de terreno del período anterior ocupaban muchos suelos que se encontraban en sectores de alta renta, en 1982, el Ministerio de la Vivienda lanza el Programa de Radicación y Erradicación de Campamentos. Este tiene por objetivos por una parte erradicar los campamentos que se encuentran en el cono de alta renta de la ciudad para localizarlos en las comunas más pobres, y por otra, radicar los situados en las periferias pobres. Miles de familias fueron desplazadas hacia las periferias surponiente de la ciudad (Rojas, 1984). Esto provocará desarraigo social y laboral, conflicto e inseguridad en las familias recién llegadas y rechazo por parte de las residentes. Además, profundizará un proceso de segregación socio espacial hasta niveles nunca antes vistos en la ciudad.

Por este programa, se construyen al sur de la nueva Comuna de El Bosque, en el costado oriente de Los Morros, cuatro poblaciones de erradicación: la Población Valparaíso, las Poblaciones El Almendro I y II y la Villa Pinochet; y se radica un campamento originado por toma de terreno: la población Carol Urzúa. Además se construye un loteo privado, la Villa Esperanza, y un conjunto de vivienda social en departamentos para familias que no se encuentran en extrema pobreza, El Tattersall. Por el costado poniente, se termina de construir por esfuerzo propio la Población General Oscar Bonilla iniciada en el período anterior, así como la Población Renacimiento construida por cooperativa. De este modo en los años 80 termina de configurarse la calle Los Morros por ambos frentes (Figura 11).

\section{0 - 2016. Los Morros, de vía a avenida con proyecto}

A 25 años de la edificación de barrios residenciales por ambos lados, Los Morros ha hecho una travesía y ha ido tomando un papel en la vida cotidiana de los habitantes de la comuna. Se ha ido conformado como la vía por donde se conectan los barrios 


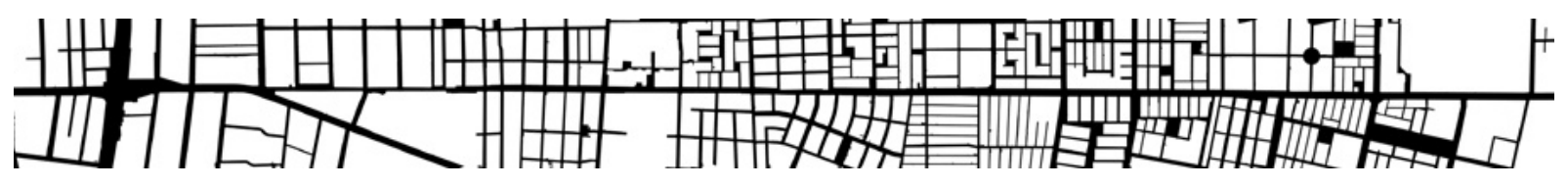

entre sí; por donde pasa el transporte público que conduce a la ciudad; en donde se ha localizado el comercio y los servicios que tienen un alcance mayor al del vecindario. Poco a poco se ha ido ganando el estatus de Avenida. Incluso ha cambiado de nombre por el de Avenida Padre Hurtado.

Su proceso de formación discontinuo a lo largo del tiempo, al son de las políticas de vivienda y de operaciones aisladas, ha dejado una huella morfológica importante en la Avenida. Huella que tiene su correlato social. Así cada villa constituye un universo con su historia y la historia e identidades de quienes la habitan, universos vertidos hacia adentro, cuyos límites están impregnados en las representaciones y en las prácticas cotidianas como fronteras sociales y espaciales. El hecho de que la avenida se haya formado como resultado de una sumatoria de urbanizaciones que deslindan con ella, también ha contribuido a que sea percibida como un límite para los barrios de su entorno, carente de un rango adecuado de espacio público y de centralidad urbana.

En lo que respecta a su huella morfológica, el tramo de la avenida que corresponde a la comuna de El Bosque se conforma por 19 barrios en su costado oriente y 17 en su costado poniente, cada uno con tramas viales, manzanas y lotes de distinto tipo, pero de edificación similar. Lo cual conforma una calle relativamente homogénea en la edificación que la bordea y muy heterogénea en los tejidos urbanos de su entorno, que responden a los estándares sociales y los periodos históricos en que se gestaron y construyeron sus barrios (Figura 12). Los más grandes, localizados en el tramo central, alcanzan un frente de $600 \mathrm{~m}$ hacia la avenida, y y los menores, localizados hacia sus extremos norte y sur, alcanzan los $80 \mathrm{~m}$. Por su parte las manzanas en torno a la avenida también son diversas. Sus superficies varían entre $665 \mathrm{~m}^{2}$ y $16.000 \mathrm{~m}^{2}$. Esta diversidad de forma y tamaño se distribuye de manera dispersa de norte a sur, produciendo algunos tramos homogéneos y otros de alto contraste. Finalmente, los predios que bordean la calle también presentan grandes diferencias que fluctúan entre $44 \mathrm{~m}^{2}$ y $500 \mathrm{~m}^{2}$. Los más pequeños se concentran en la mitad sur de la avenida y los grandes hacia el extremo norte, siguiendo los estándares de vivienda con que fueron construidos.

\section{La avenida y la vida pública}

A pesar de la diversidad de sus frentes, a primera vista la avenida presenta un paisaje aparentemente homogéneo. Sin embargo su diversidad se manifiesta en la forma de fronteras sociales invisibles tanto de norte a sur como entre sus costados oriente y poniente. En un lado y otro de la avenida habitan comunidades de distinto origen, historia y situación socioeconómica, por un lado trabajadores que habitan barrios construidos por promoción privada o institucional, y por otro pobladores que habitan villas de vivienda social. Entre ambos se miran mutuamente desde lugares e identidades distintas. Unos prefieren circular por Gran Avenida, los otros lo hacen por Los Morros. Del mismo modo, quienes habitan hacia el norte consideran insegura la avenida hacia el sur. Sin embargo a toda hora la avenida tiene animación, al mediodía con las mujeres en las compras, los vendedores en la calle, los comerciantes y los trabajadores manuales, en la tarde con la salida de los colegios, hacia la noche con la llegada del trabajo y en los fines de semana, en el mercado Persa.

Desde el punto de vista de su vocación como espacio público, es evidente que Los Morros es una calle que no ha sido pensada o proyectada como tal. No obstante la diversidad de las tramas de los barrios que la colindan, el espacio público (Figura 13) muestra una vía
Figura 12. Trama de espacio público del eje Los Morros y su entorno cercano, entre Américo Vespucio (izq.) y hospital el pino (der.). Fuente: Elaborado por los autores. 

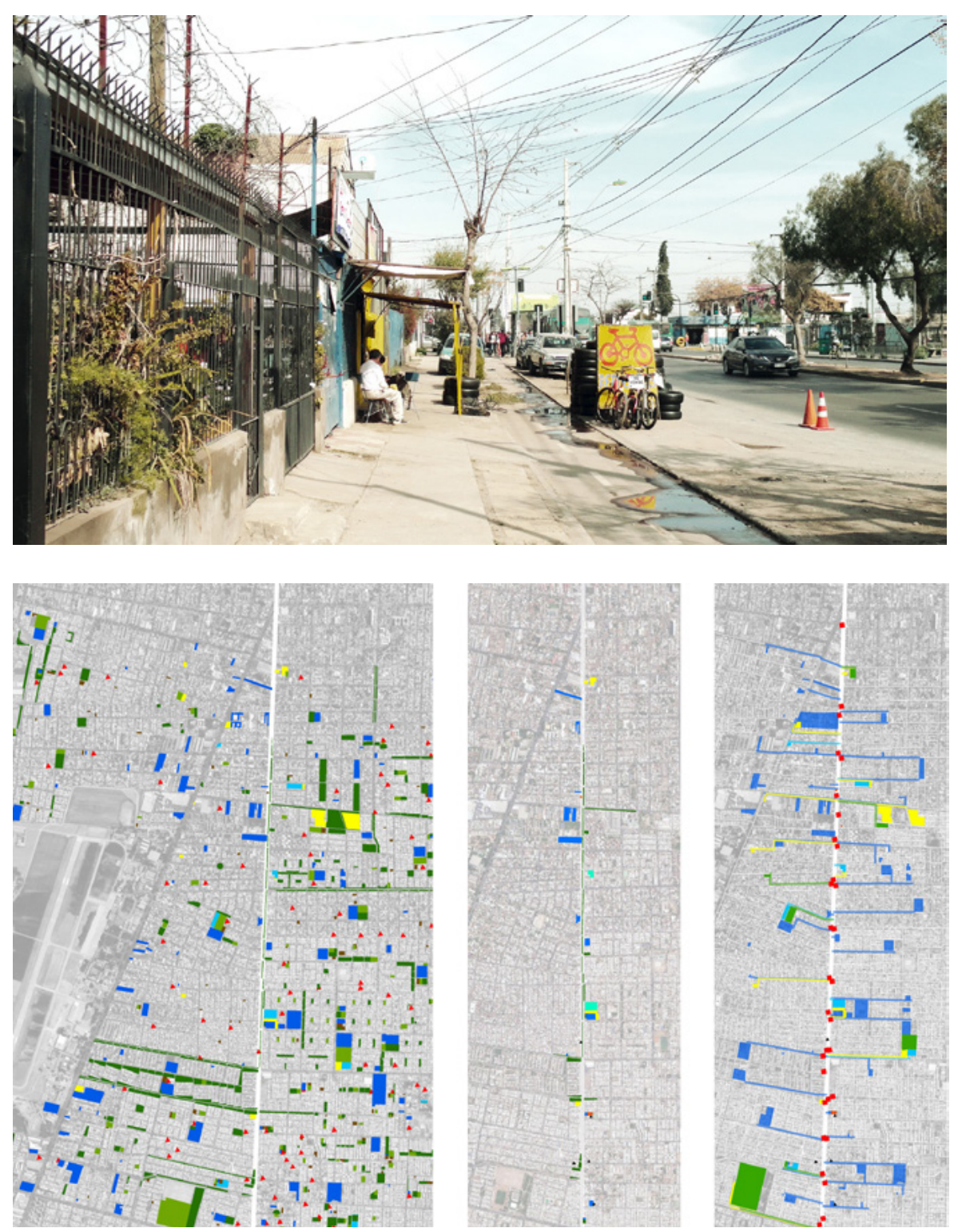

con pocas fluctuaciones en su perfil, con un ancho relativamente homogéneo de entre 26 y $30 \mathrm{~m}$ casi en toda su longitud, casi carente de articulaciones espaciales significativas -parques, plazas, plazoletas, atrios, etc.- que modifiquen su forma lineal, y afirmen una vocación de espacio público. Sin embargo, presenta un potencial importante de lugares que los habitantes marcan como espacio público en sus prácticas cotidianas.

En contraste, en coherencia con el mosaico de villas que constituyen este territorio, hacia el interior de los barrios la trama de espacios públicos es muy diversa. Prácticamente cada barrio fue proyectado con un porcentaje de espacio para plazoletas, plazas, canchas, parques lineales, equipamientos, etc. (Figura 14 A y B). A esta concentración de equipamientos y áreas verdes en los interiores de cada población se suma la política municipal, que habiendo recibido de la dictadura militar un territorio empobrecido y amenazado, ha debido desplegar desde hace 25 años iniciativas destinadas a generar cohesión social en sus unidades barriales, mediante participación social y planes de mejoramiento de sus espacios públicos.

El fuerte contraste de la distribución de las áreas verdes y los equipamientos públicos en el interior de los barrios y la avenida, evidencia la condición de límite antes mencionada
Figura 13. Avenida Los Morros (actual Padre Hurtado). Muestra la actividad de la calle, animada por el comercio por cuenta propia en primer piso y la vivienda en segundo piso. Fuente: Magdalena García.

Figura 14. A: Equipamiento y espacios públicos en la comuna El Bosque. B: Equipamiento al borde la avenida Los Morros. C: Equipamiento en torno a 600 $\mathrm{m}$. de la avenida y su relación con los paraderos de buses. Fuente: Elaboración autores. 

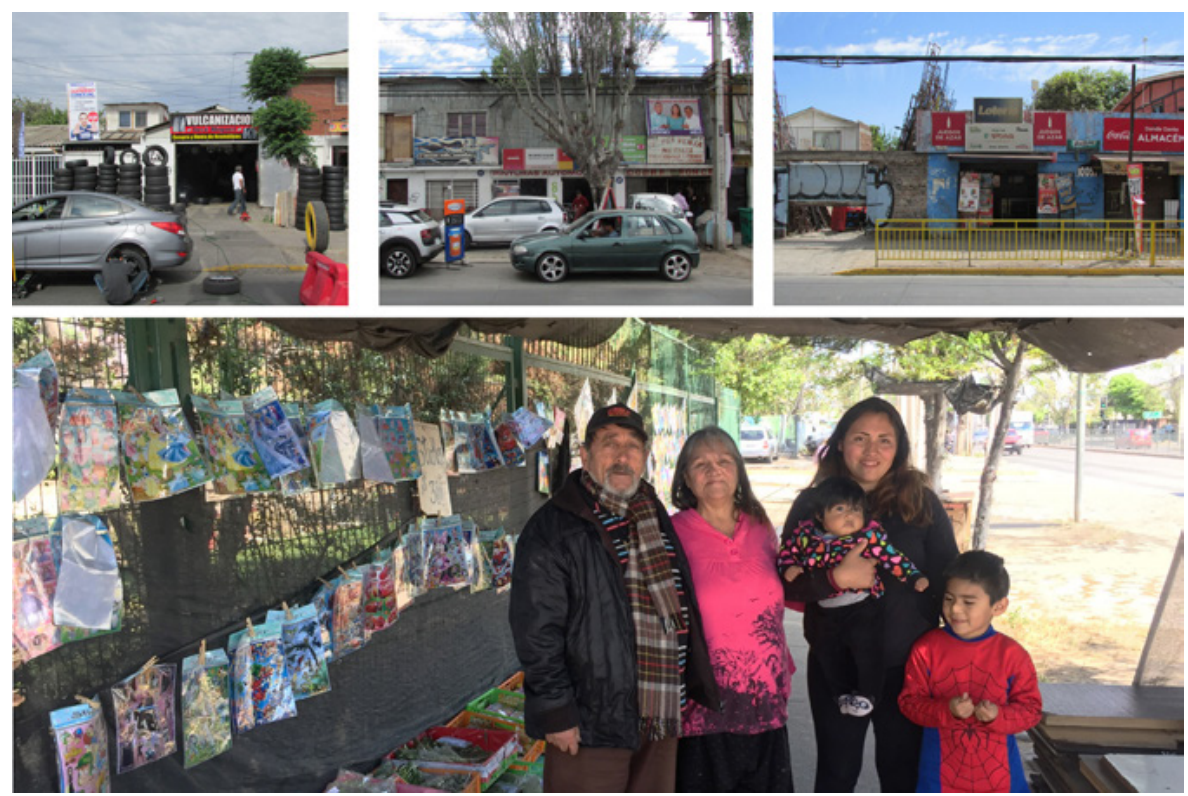

de Los Morros. La cual aparentemente le resta estatus jerárquico y no contribuye a intensificar la vida pública en ella. Sin embargo dada la escasa conectividad interna de los barrios, la accesibilidad hacia y entre ellos se organiza desde la avenida. El plano (Figura 14 C) da cuenta de la relación entre la ubicación de los paraderos de transporte público y las calles transversales que conducen a los distintos equipamientos educacionales, de salud, de culto, deportivos, municipales, y culturales de escala comunal y vecinal, ubicados a $600 \mathrm{~m}$ de distancia desde la avenida. Esta imagen da cuenta de las relaciones que se han establecido entre el transporte público que transita por la avenida y los equipamientos al interior de los barrios y por lo tanto de los potenciales de conectividad que ofrece la avenida entre ellos.

\section{La avenida del comercio y los servicios}

Es la actividad comercial y de servicios la que anima la vida pública de Los Morros. Un comercio mayoritariamente de iniciativa local y de base familiar que se instala en negocios especializados, en recintos abiertos en los frentes de las casas, en puestos fijos instalados en las veredas, en carros ambulantes o en las ferias y el Mercado Persa. Es allí donde se encuentra la gente de distintos barrios, donde los comerciantes son conocidos o vecinos, donde se cuentan los acontecimientos, se comparten los problemas, se organizan los apoyos comunitarios, se trabaja en familia, se compra y se vende en porciones y a precios accesibles. Donde se reconocen las identidades más allá de los límites del barrio.

En los $5 \mathrm{~km}$ del tramo en estudio, la Av. Los Morros registra actualmente 310 locales de comercio y servicios (Figura 15), un $40 \%$ de los cuales se localiza al costado oriente y un $60 \%$ al poniente. Es posible que el mayor número de locales en el borde poniente refleje las diferencias en las condiciones sociales, económicas y morfológicas de los barrios entre un borde y otro de la avenida, aunque también podría relacionarse con el hecho de que en los barrios del oriente hay mucho más actividad comercial casera diseminada en el interior. La mayor concentración de locales coincide con las poblaciones más antiguas de la avenida y tiende a fijar un centro en su cruce con la Avenida Observatorio antiguo camino transversal que conducía hasta el acceso del Observatorio Astronómico (Figura 16), donde hoy se concentra la mayor cantidad de paraderos de buses.

Desagregando en rubros, predomina el comercio de proximidad que vende alimentos (almacenes, panaderías, carnicerías, comida rápida, etc.) donde se compra al día y
Figura 15. La vida comercial de la calle. Fuente: Michael Arriagada y Camila Torreblanca. 


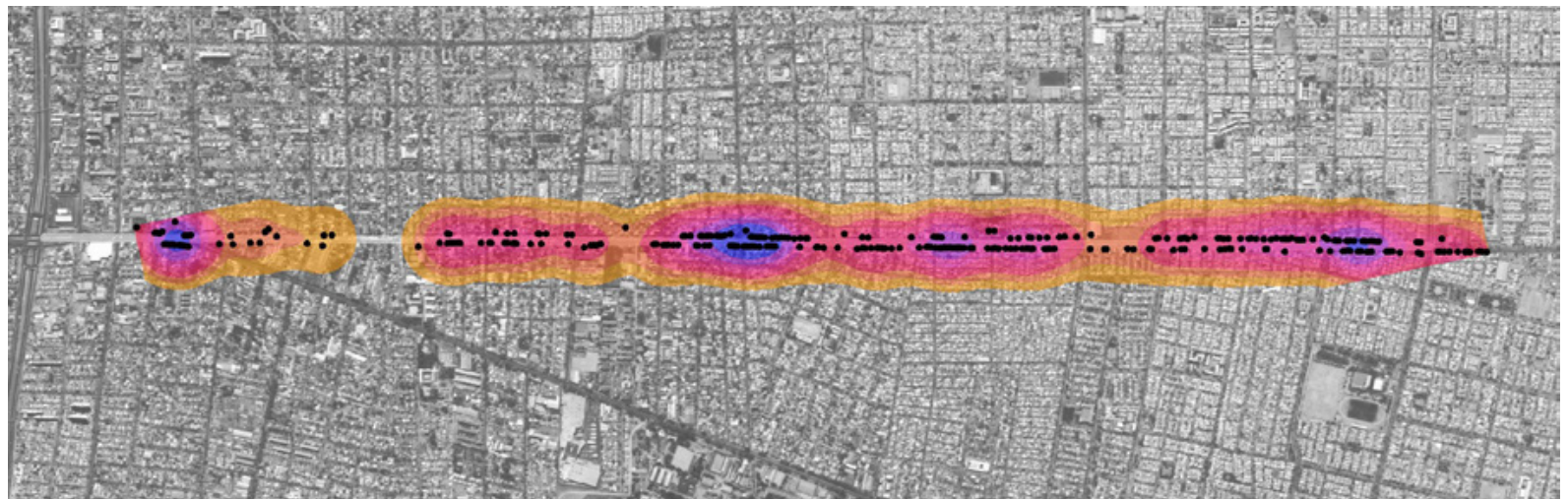

en porciones pequeñas como decíamos arriba, debido a que los vecinos, en gran parte trabajadores por cuenta propia, juntan sus ingresos cada día, cada semana o cada quincena. Este rubro concentra más de un tercio del total de los locales y se distribuye a lo largo de toda la avenida. En segundo lugar curiosamente se encuentra el comercio automotor (talleres, venta de repuestos, vulcanizaciones, etc.), es posible que esto se deba a la compra de autos usados que aumenta en los barrios debido a la mala calidad de los servicios de transporte público. En un rango menor aparecen otras actividades como la salud, la construcción, las botillerías, los centros de estética y de mascotas (Figura 17).
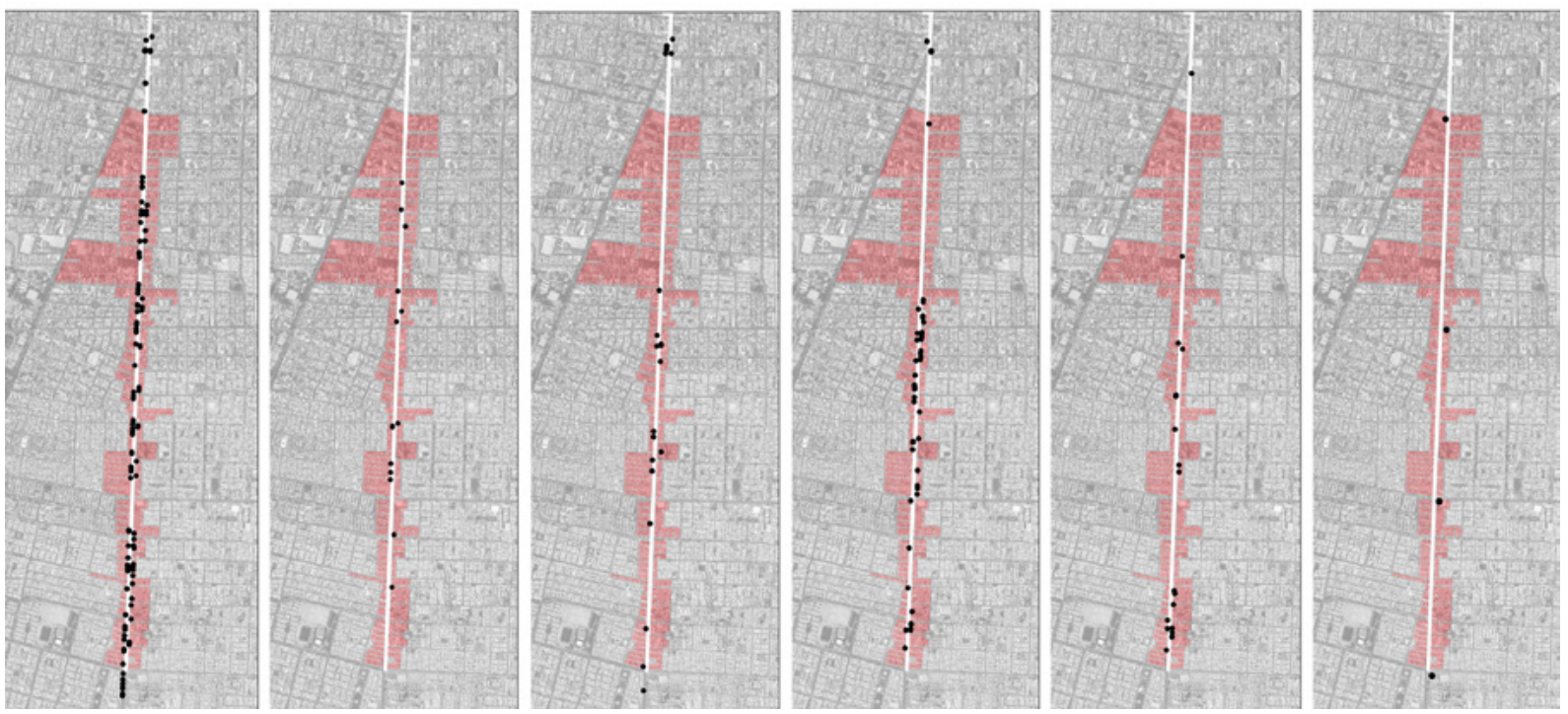

Figura 17. Rubros comerciales en la avenida. De derecha a izquierda: alimentación, botillerías, salud, automotor, construcción y supermercados. Fuente: Elaboración autores.
Figura 16. Distribución y gráfico de densidad de locales comerciales en avenida Los Morros. Fuente: Elaboración autores.

El tipo de comercio más tradicional en los barrios populares de nuestras ciudades son las ferias. Como dice Gabriel Salazar, ellas son desde antaño los espacios de soberanía del bajo pueblo donde se construye, se preserva y se ejerce su identidad. La comuna de El Bosque recibe en sus calles semanalmente una gran cantidad de ferias libres que representan alrededor del $40 \%$ de sus patentes comerciales. En la Avenida Los Morros se instala todos los fines de semana, desde hace más de 40 años, el mercado "Persa de Los Morros", lugar de abastecimiento de vestuario, calzado, ropa blanca, productos de belleza, accesorios, enseres de cocina, electrodomésticos, herramientas, ferretería, libros nuevos y usados, alimentos procesados, comida preparada. Este es el lugar por excelencia de paseo donde se cruzan y encuentran visitantes de todos los barrios, e incluso de barrios de otras comunas. Se apropia de la avenida los días 


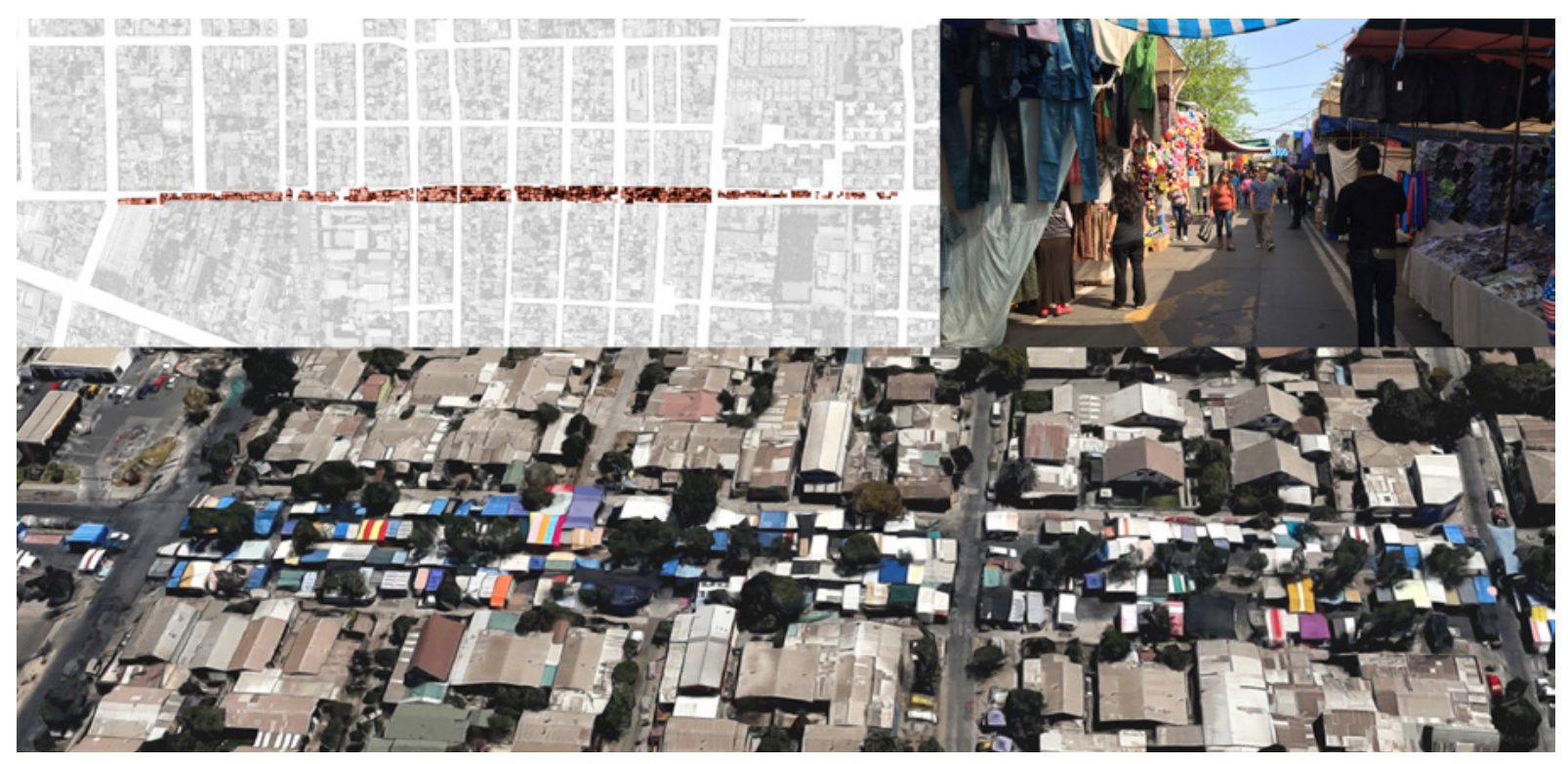

sábado y domingo ocupando casi un kilómetro y medio entre las calles Riquelme y Alejandro Guzmán (Figura 18). En él se levantan cerca de 1.200 puestos regulares y una cantidad variable de "coleros" -o puestos sin permiso- según los ciclos de mayor o menor empleo en el sector formal o informal. Se trata de una verdadera institución social que hace de esta avenida un espacio público vibrante y mutante entre semana $y$ fin de semana.

Su implantación interviene no sin conflictos sobre la avenida, su espacio público y su entorno, sin embargo, las propiedades del borde también participan en él, ya sea como bodegas de las estructuras de los puestos, ya sea proveyendo servicios higiénicos, o bien como negocios ocasionales que aprovechan la actividad y la aglomeración que convoca, para la venta de comida rápida, bebidas o café. Por otra parte provoca ciertamente un cambio radical en la percepción y la función de la avenida los fines de semana. El transporte público y los vehículos particulares deben utilizar rutas alternativas para sortear el tramo ocupado, mientras los puestos y los peatones se hacen de la calle. La espacialidad de la calle también cambia, se transforma en un pasillo comercial interior que en tramos más anchos de la avenida se duplica. Allí se recrea la comunidad al tiempo que se comercia o se hace una pausa para conversar o comer. Un verdadero paseo popular.

\section{La trama vial, conectividad y confinamiento del territorio}

La trama vial en torno a la Avenida Los Morros presenta una morfología particular, que es herencia del proceso de subdivisión de los predios agrícolas del Llano y de la lógica de urbanización fragmentada que le siguió, y contribuye al confinamiento espacial y social de sus barrios al mismo tiempo que asigna a Los Morros un papel jerárquico en la movilidad cotidiana (Figura 12).

En sentido transversal a la avenida, los caminos que perduran de la subdivisión predial de 1820 con intervalos promedio de $1,28 \mathrm{~km}$, corresponden a las actuales avenidas Riquelme-Aviadores, Alejandro Guzmán, Observatorio, Lo Martínez y Lo Blanco. Estas son las que aseguran la conectividad oriente-poniente entre ambos lados de Los Morros, una de las cuales tiene alcance intercomunal. Al interior de esta macro trama vial, las tramas internas de los barrios rara vez tienen continuidad transversal o paralela a la avenida, lo cual refuerza una suerte de enclave territorial y social de los barrios entre sí y con el resto de la comuna y la ciudad. De un total de 87 calles que
Figura 18. Feria Persa de la Avenida Los Morros. Cuenta con 1.200 locales a lo largo de $1,3 \mathrm{~km}$, entre las calles Riquelme y Alejandro Guzmán. Fuente: Google Earth (visitado 15 octubre, 2016), fotografía Camila Torreblanca, plano Christian Saavedra. 


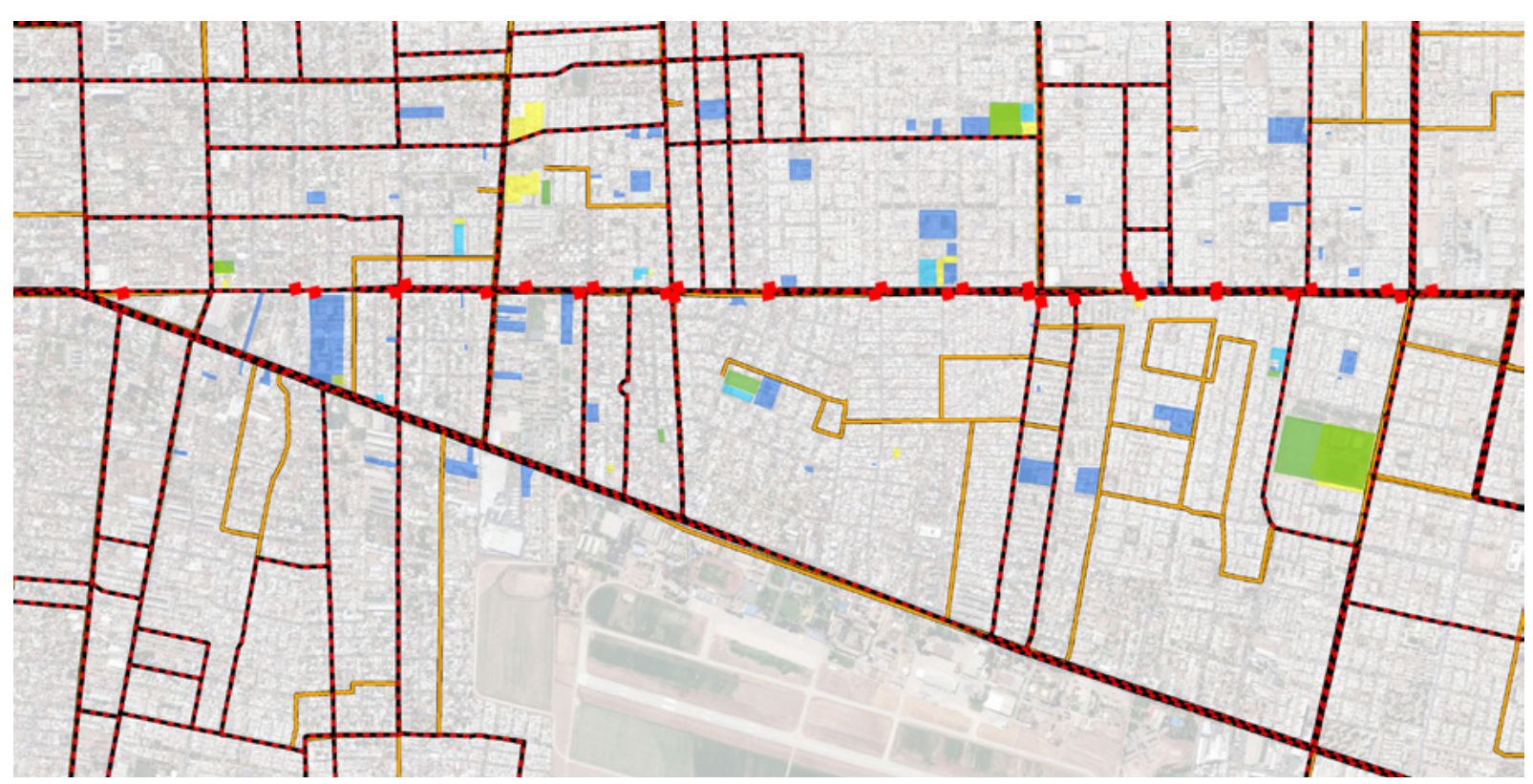

llegan a Los Morros, solo 15 presentan continuidad y las 72 restantes no empalman entre sí a ambos lados de ésta. Esta situación solicita a la avenida como un espacio de conectividad y transición entre los barrios y hacia la ciudad, y confirma su rol como vía principal, por donde la gente está obligada a circular.

Igual situación ocurre en sentido norte-sur, las calles de los barrios contiguos no tienen continuidad entre sí. Las rutas alternativas a la avenida Los Morros por el interior de las villas son discontinuas, llenas de quiebres y de perfiles diversos. Lo cual vuelca las salidas y la mayor parte de los desplazamientos de transporte público y privado desde los barrios hacia las avenidas Los Morros y la Gran Avenida, a través de las calles principales de la macro estructura de 1820, mencionada más arriba.

\section{La avenida y los viajes cotidianos}

Por la avenida circula una gran proporción de los viajes cotidianos especialmente del sector oriente y sur de la comuna. En El Bosque predominan los viajes a pie, cuando hay que alcanzar distancias mayores acompañando niños y adultos mayores, las mujeres prefieren el taxi colectivo. Lo mismo ocurre para llegar de noche en sectores inseguros o para acercarse hasta el Metro si los destinos son fuera de la comuna. Para ir de un barrio a otro, las trayectorias se hacen preferentemente por Los Morros para no atravesar barrios que son ajenos. Los hombres viajan al trabajo de preferencia compartiendo automóvil, en autobús o en bicicleta. El transporte público en la Avenida Los Morros se compone de servicios de buses de Transantiago y de taxis colectivos que a pesar de ser a veces más caros, son preferidos a los buses cuyos servicios son mal evaluados por parte de los usuarios (Figura 19).

\section{De avenida sin proyecto a un proyecto de avenida}

Han pasado veinticinco años desde que la Comuna de El Bosque fue creada, tomando a su cargo un territorio diverso que cuenta al menos doscientos años de formación, habitado por grupos sociales también diversos no sólo en los rangos socioeconómicos y laborales, sino también identitarios, e incluso ideológicos, que son parte de la historia de su poblamiento desde que fue destino en los días de solaz de las aristocracias
Figura 19. Trama de transporte público y equipamiento en torno a la Avenida Los Morros. Línea negrorojo: bus; línea naranja: taxis colectivos; puntos rojos: paraderos buses. Fuente: Elaboración autores. 
santiaguinas, hasta ser destino de pobladores sin casa, pasando por los tiempos en que acogió trabajadores y empleados asalariados. Una historia que refleja el poblamiento de la ciudad desde la República. La Avenida Los Morros es un espejo de esta trayectoria, e incluso le precede por varios siglos.

Conformado hoy por una superposición de operaciones de vivienda que se fueron instalando en sus bordes al ritmo de las compraventas privadas o públicas de predios al mejor postor, este antiguo camino hoy avenida periférica como muchas otras de nuestra ciudad, refleja el mosaico de su entorno. Hasta poco tiempo atrás no ha sido más que el límite de los barrios con que colinda y una vía de acceso a la ciudad. Así lo muestran tanto los relatos de la gente que la transita como los planos que han orientado la acción municipal hasta hoy. Una vía a la imagen y semejanza del territorio que la circunda, que Salazar describe así:

[La comuna de El Bosque] se sitúa en la zona sur del Gran Santiago que suele ser calificada como parte del cinturón de pobreza que rodea los distritos centro-este de esta ciudad [...]. Sin embargo, pese a su ubicación en el señalado 'cinturón' no es, como muestran los datos estadísticos, una comuna de "pobreza integral"; tampoco de "pobreza por retraso", sino más bien de "pobreza moderna" (pobreza que convive con la modernidad), si bien se sitúa en el margen externo de Santiago, en el límite mismo con lo rural, su composición global muestra sectores antiguos (semi-rurales), con otros modernos (los próximos a la Gran Avenida) y poblamientos por toma de terreno tanto como por construcción de villas de nivel medio. Podemos apreciar además una ausencia de grandes centros comerciales, sectores industriales o de otro carácter definido [...] la mayoría de su fuerza de trabajo labora, al parecer, fuera de los límites comunales. Podría decirse que no tiene una articulación definida que le otorgue identidad reconocible, ni presenta polos de desarrollo económico o material significantes. Tampoco es representativa de la extrema pobreza. (Salazar, 1997: 20-21, extraído de Muñoz, 2004)

En el transcurso de estos veinticinco años, esta vía, que en su condición de camino fue por largo tiempo frontera entre barrios diversos y discontinuos que fueron disponiéndose en su entorno, se ha ido ganando su estatus de espacio público, lugar que deja de ser de paso para acoger las prácticas cotidianas de personas diversas, lugar en que converge y habita la diferencia, lugar en que se reconocen quienes habitan en su entorno. Y así paulatinamente ha ido transformándose de camino en avenida.

Este viejo camino del sur, posible ruta indígena conducente a los valles agrícolas allende el río Maipo, que ha perdurado durante siglos, que se ha transformado en calle larga en torno a la cual fue creciendo la ciudad más allá de sus límites. Este camino que ha mantenido su carácter periférico -o conducente a la periferia de la ciudad-, que atraviesa una comuna sin centro, se encuentra hoy en condiciones de convertirse en avenida con proyecto. "Una avenida amigable e inclusiva", así lo expresan los relatos de su gente cuando imaginan su futuro frente a las transformaciones que están a la puerta.

Hoy convergen iniciativas de distintas instituciones públicas que podrían hacer de ella un espacio público mayor de la comuna. Por una parte, el municipio la proyecta por primera vez como una entidad unitaria y jerárquica en su plan regulador que está por aprobarse, y le asigna una centralidad respecto a su contexto inmediato (Figura 20b). A diferencia de la representación y el proyecto que tenía para ella el plan regulador que llega a su fin (Figura 20 a), en el futuro la avenida aparece como un espacio de vinculación entre los barrios, una avenida principal de comercio y residencia en altura media.

Por otra parte, Metro extenderá su Línea 2 hacia el sur con cuatro estaciones que se proyectadas a lo largo de la Avenida Los Morros (Figura 21). Esta decisión modificará 

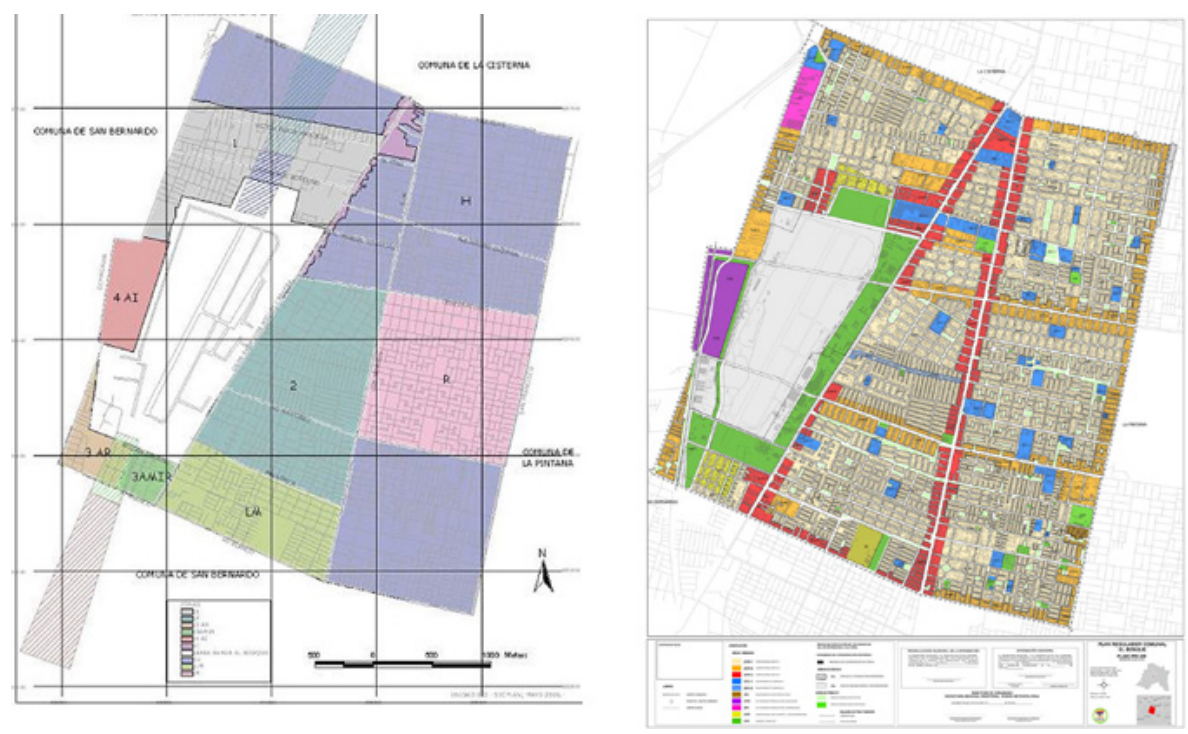

la organización de los servicios del sistema de buses de Transantiago que por su parte está por iniciar una nueva etapa de mejoramiento sustancial de la calidad de sus servicios, así como la renovación de sus paraderos a lo largo de la avenida. Finalmente, la Secretaría Regional Ministerial Metropolitana de Vivienda y Urbanismo contempla renovar los pavimentos en todo su largo.

\begin{abstract}
A finales de mayo de 2016 Metro de Santiago anunció la extensión de la actual línea 2, en 5,1 km hacia el sur, por Avenida Los Morros hasta el Hospital El Pino, para estar operativa a fines de 2021[...] Considera cuatro estaciones nuevas a una distancia promedio de 1,3 km: Lo Espejo, Observatorio, Lo Martínez y Hospital El Pino. Se estiman 216.00o pasajeros potenciales diarios. (Extracto de prensa 24h)
\end{abstract}

Pocas veces se concentran al mismo tiempo en una misma avenida las decisiones y las iniciativas de las distintas instituciones que tienen responsabilidad sobre ella. Estas iniciativas son susceptibles de impulsar un nuevo escenario de diseño para la avenida y de desarrollo para la comuna. La llegada del Metro reforzará la conectividad de estos barrios relegados de la ciudad con sus centros de actividad y con el resto de la red de transporte público, mejorando sustancialmente los viajes cotidianos de sus residentes tanto en calidad como en tiempos de viaje. Los $15 \mathrm{~km}$ de trayecto entre Hospital El Pino en su extremo sur y la estación los Héroes, en la Alameda Bernardo O’Higgins, se estiman en 28 minutos.

En lo que se refiere a la calidad de su espacio público, la posibilidad de rehacer su pavimentación permitirá replantear las jerarquías de los desplazamientos y remodelar su paisaje, redistribuir y reorganizar el espacio de los medios de desplazamiento, priorizar por los miles de peatones que la transitan a diario, rediseñar sus veredas para dar lugar a la vida social cotidiana y al paseo. Las estaciones de Metro permitirán dotarla de nuevas centralidades, y las paradas de buses, de lugares confortables y seguros. Por su parte, el nuevo Plan Regulador Comunal abre la posibilidad de elevar las alturas de la edificación del entorno y de hacer de ella una avenida de comercio, trabajo y servicios.

La Avenida Los Morros está hoy en condiciones de iniciar un nuevo ciclo como espacio público vibrante, inclusivo y de calidad para los barrios del entorno. Pero estos potenciales también traen consigo una serie de desafíos en una economía regida por los mercados y un desarrollo urbano basado en un sector inmobiliario con escaso sentido de interés público. Para ser coherentes con su historia social, habrá que generar condiciones para promover la economía local y densificar asegurando la permanencia
Figura 20. Plan Regulador Comunal de El Bosque. A: vigente y B: proyecto. Muestra la nula relevancia que la Comuna le asigna a la Avenida Los Morros el Plan vigente y la importancia que le otorga al que se encuentra en proceso de aprobación (B). Fuente: Municipalidad de El Bosque. 


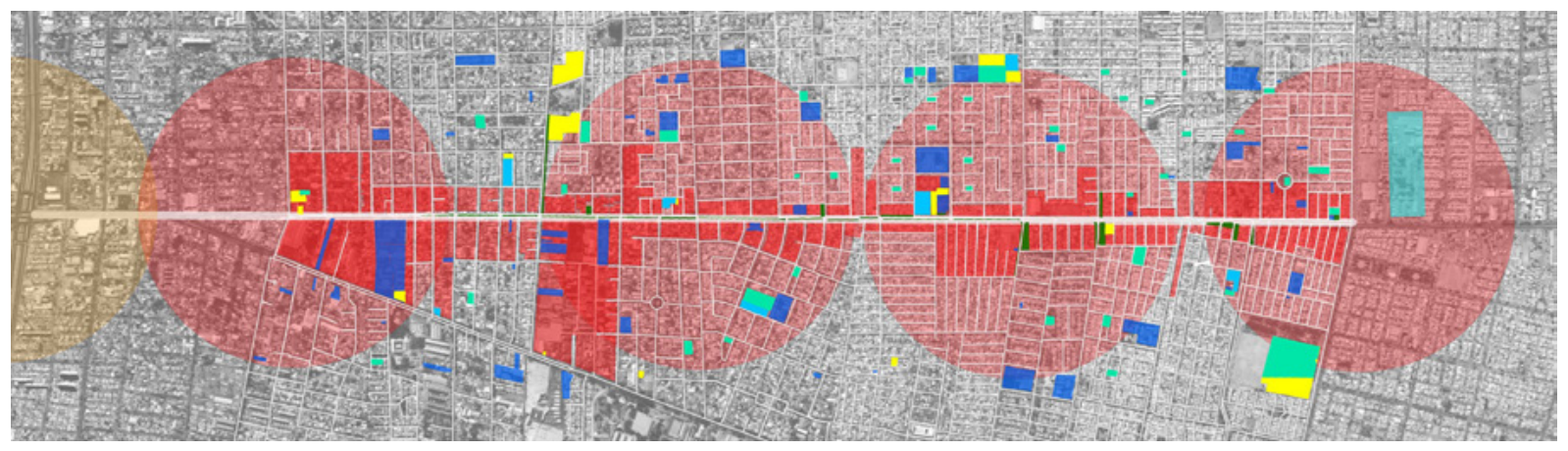

de sus habitantes frente a las presiones que se ejercerán desde el mercado inmobiliario, como ocurre con la llegada del Metro y el mejoramiento del espacio público en muchos otros lugares de la ciudad. Ello implica imaginar un "Proyecto" que recoja y exprese los modos específicos de ser, estar y habitar que han hecho su historia.

\section{Para concluir}

Esta avenida no es una excepción en nuestras ciudades, tampoco lo es en el contexto latinoamericano. Desde períodos precolombinos, la conquista, el control y la comunicación a distancia de vastos territorios que proveían alimentos, minerales, fuerza de trabajo, sentaron las bases para la configuración de sistemas de ciudades y pueblos agrícolas o mineros, sitios militares y puertos, articulados por rutas y caminos cuyos trazados han perdurado a lo largo de los distintos períodos de formación de nuestras ciudades y han dado forma a las arterias principales de las periferias urbanas, escasas vías de acceso a la ciudad más allá del barrio.

Rutas de comunicación y transporte desde los imperios precolombinos, caminos rurales en la colonia, ejes de operaciones urbanas desde los albores de la independencia, se han transformado paulatinamente en arterias de concentración de servicios y comercio, de emplazamiento de los equipamientos públicos, ejes de desplazamiento de las centralidades, vías troncales del transporte, que poco a poco van cobrando intensidad cívica y estatus de avenidas. En torno a ellos se ha ido estructurando el patrón de crecimiento radioconcéntrico que caracteriza a las ciudades latinoamericanas en mayor o menor grado, según el asiento geográfico en que fueron fundadas. Un crecimiento que ha ido desplazando hacia las afueras de la ciudad a las poblaciones menos favorecidas para quienes estas avenidas constituyen espacios públicos mayores de interacciones sociales de diverso tipo, y en especial, de acceso a la ciudad y sus oportunidades. En Santiago podemos nombrar unas cuantas que conducen hacia las periferias de menores ingresos, Independencia y Recoleta al norte, San Pablo al poniente, Ochagavía, Gran Avenida Los morros, Santa Rosa y Vicuña Mackenna al sur, y hacia el cono de mayores ingresos al oriente, Apoquindo y Vitacura. Es muy posible que si observamos ciudades latinoamericanas, las encontraremos con orígenes, características y potenciales similares.

Los Morros es una más de muchas avenidas periféricas que otrora fueron caminos y se han configurado como centros lineales en el tiempo, lugares esenciales para la vida de los barrios de su entorno, en que se expresan sus identidades y sus diferencias, lugares de intercambio y transición hacia la ciudad. Estos caminos que han forjado en el tiempo su propia urbanidad, alejadas del diseño y la planificación, han adquirido por mérito propio estatus de calle. La ciudad está en deuda con ellas, en adelante debieran adquirir forma y estatus de Avenidas de primera jerarquía cívica, y esto es posible, la llegada del Metro es ya una señal de su importancia local y metropolitana.
Figura 21. Extensión de la línea 2 de Metro por avenida los morros, con cuatro estaciones, hasta el Hospital El Pino y equipamiento, manzanas de borde y radios de $600 \mathrm{~m}$ en torno a estaciones proyectadas. Fuente: Elaboración autores. 
Un estudio de largo período como el aquí propuesto, permite comprenderlas en su especificidad, es decir como producto de modos específicos de habitar y hacer ciudad, para desde allí proyectar su futuro. Tomar distancia de -o contribuir a transformar- los enfoques, los principios y las prácticas institucionales desde los cuales se las diseña y planifica de manera acrítica y funcionalista, como parte de la vialidad urbana o como infraestructuras del transporte público, que a poco andar suelen desmantelar todos sus otros atributos y funciones sociales, económicas y culturales.

Este artículo forma parte de la investigación sobre las Calles Integrales del Centro de Desarrollo Urbano Sustentable, CEDEUS, Pontificia Universidad Católica de Chile, al cual agradecemos el apoyo a la elaboración de este texto. 


\section{Q Bibliografía}

》 ARZE, Elías (1987) La dirección de proyectos en Chile. Revista de Ingeniería de la Construcción, №2, Marzo 1987, pp. 16-19.

» CORREA, Onofre (1984) La cisterna abre la puerta a su pasado. Santiago de Chile: Editorial Antártica.

" CORREA, Magdalena; VALENZUELA, Christian (2013) Representación, ciudad y hechos del territorio: Santiago de Chile: 1730-1831. Barcelona: UPCommons, Universidad de Catalunya, http://upcommons.upc.edu/handle/2099/14122 (visitado 19 enero, 2017).

»DE LILLO, Ginés (1942 [1602-1605]) Mensuras Ginés de Lillo. Colección de HIstoriadores de Chile y de documentos relativos a la historia nacional. Tomo XLIX. Santiago de Chile: Imprenta Universitaria.

»DE RAMÓN, Armando (2000) Santiago de Chile (1541-1991) Hlstoria de una sociedad urbana. Santiago de Chile: Editorial Sudamericana.

» ECHAíZ, René León (1975) Historia de Santiago, Tomo II La República. Santiago de Chile: Imprenta Ricardo Neupert.

» ERRÁZURIZ, Tomás (2014) La administración de lbáñez Del Campo y el impulso a la circulación moderna (Santiago, 1927-1931), Rev. Historia (Santiago) vol. 47, ํㅡ. Santiago de Chile. http://www.scielo.cl/scielo.php?script=sci_arttext\&pid=So71771942014000200002\#n50 (consultado 18 de diciembre, 2016).

» FORRAY, Rosanna; FIGUEROA, Cristhian; HIDALGO, Rocío (2013) De Camino del Inca a Gran Avenida. Rev ARQ 85, pp. 36-47.

» GARCÉS, César (2000) Procesos de urbanización y condiciones ambientales en áreas urbanas periféricas. el caso de la comuna de El Bosque. Tesis Magíster en Asentamientos Humanos y Medio Ambiente, Pontificia Universidad Católica de Chile.

» HIDALGO DATTWYLER, Rodrigo (2005) La vivienda social en Chile y la construcción del espacio urbano en el Santiago del siglo XX. Santiago de Chile: Ediciones de la Dirección de Bibliotecas, Archivos y Museos.

» MINISTERIO DE VIVIENDA Y URBANISMO (2006) Chile, Un siglo de políticas de vivienda y barrio. Santiago de Chile: Gobierno de Chile.

» MUÑOZ ARIAS, Anisia (2004) Soberanía e identidad popular: sociabilidad en las ferias libres de la comuna de El Bosque en la segunda mitad del siglo XX. Anuario de Pregrado. ISSN 0718-2848.

»PÉREZ ROSALES, Vicente (1886) Recuerdos del Pasado 1814-1860. Santiago de Chile: Imprenta Gutenberg.

» ROMERO, Marcelino (2016) De la llanura inmensa, pedregosa y desierta a la bella ciudad, un acercamiento a la historia de San Bernardo desde su poblamiento hasta 1920. En Rojas Morales, Luis y Cárdenas, Romero (2016) Engranajes de la memoria. Puesta en valor del patrimonio de la Maestranza Central de San Bernardo. Santiago de Chile. https://www.colectivorescata.wordpress (visitado 15 enero, 2017)

» ROJAS, Sergio (1984) Políticas de Erradicación y Radicación de Campamentos. 1982-1984, Discursos, logros y problemas. FLACSO Chile, Documento de Trabajo №215. 
»SALAZAR, Gabriel (1992) La mujer de “bajo pueblo" en Chile: bosquejo histórico. En Sur Proposiciones No 21, pp. 64-83.

»SALAZAR, Gabriel (1997) Droga y Comunidad local. Economía, sociedad y política. El caso de la comuna de El Bosque (1982-1997). Santiago: SUR.

»COMISIÓN DE TRABAJO AUTÓNOMO MAPUCHE (2003) Territorio y Tierras Mapuche. Informe de la Comisión Verdad Histórica y Nuevo Trato 2003, Primera parte del informe final de la Comisión de Trabajo Autónomo Mapuche, Volumen III, Tomo II, Capítulo II.

»S/a (S/f) BIBLIOTECA NACIONAL DE CHILE. “Chinganas”, en: La cueca. Memoria Chilena. Disponible en http://www.memoriachilena.cl/6o2/w3article-93129.html. Accedido en 15/4/2017.

» S/a (S/f) Guía Patrimonial de San Bernardo, Universidad de Los Andes.

»S/a (1910) Población Villa Italia, La Cisterna. Santiago (Chile): Imprenta Barcelona.

»STEHBERG, Rubén (1995) Instalaciones incaicas en el norte y centro semiárido de Chile. Santiago de Chile: Dirección de Bibliotecas Archivos y Museos.

»STEHBERG, Rubén y SOTOMAYOR, Gonzalo (2012) Mapocho Incaico. Boletín del Museo Nacional de Historia Natural, Chile, № 61, pp. 85-149.

» TORRES GANDOLFI, Carlos (1997) Valle de Santiago. Notable mapa hasta hoy inédito, ejecutado por el Capitán don Nicolás de Abos y Padilla. 17 de febrero de 1746. En: Asociación de Canalistas (Chile) (ed.) Sociedad del Canal de Maipo: 170 años, pp.46-48. Disponible en Memoria Chilena, Biblioteca Nacional de Chile http://www.memoriachilena.cl/6o2/w3-article-9787.html . Accedido en 20/04//2017.

» VIVAR, Gerónimo (1966 [1558]) Crónica y relación copiosa y verdadera de los Reinos de Chile. MDLVIII. Santiago: Fondo Histórico y Bibliográfico José T. Medina.Tomo II, $214 \mathrm{p}$.

» VICUÑA MACKENNA, Benjamín (1997[1869]) Historia de Santiago. El canal de San Carlos. En: Santiago: Asociación de Canalistas (Chile). Sociedad del Canal de Maipo : 170 años . Disponible en Memoria Chilena, Biblioteca Nacional de Chile http://www.memoriachilena.cl/6o2/w3-article-9787.html . Accedido en 28/9/2017.

» Extracto de prensa 24 horas. http://www.24horas.cl/nacional/metro-de-santiagoanuncia-extensiones-en-dos-lineas-para-el-2021-2027430

\section{Rosanna Forray / rforray@uc.cl}

Arquitecta, PUC, Master of Science y Doctora PhD en Ciencias Aplicadas, Universidad Católica de Lovaina. Profesora asociada y Jefe de Línea Ciudad y Paisaje en la Escuela de Arquitectura, Facultad de Arquitectura, Diseño y Estudios Urbanos de la Pontificia Universidad Católica de Chile. Es miembro de CEDEUS, Centro de Desarrollo Urbano Sustentable y del Laboratorio de Ciudad y Movilidad UC.

\section{Christian Saavedra / cxsaaved@uc.cl}

Arquitecto, UNAB, Magister en Arquitectura PUC. Profesor en las escuelas de Arquitectura de la UNAB y de la Pontificia Universidad Católica. Se desempaña como docente e investigador en métodos de representación, cartografía histórica, ciudad, paisaje y movilidad. 